\title{
3 Truths for Whiteness
}

\subsection{Sylvia Wynter's conception of being hu/man}

\author{
Adapting truths: historicizing humanism
}

In the introduction, I suggest that the three investigative frames of this project intuition, play, and humor - all mobilize some notion of "the human" in theory, practice, and analysis. Paul Sills, for example, states: "I think improvisational theater and my mother's work are attempts [...] to go into the possibilities of human development" (qtd. in Sweet 17), and that "theater is responsible for the image of the human [and] the concerns of the artists are the concerns of the people" (qtd. in Sweet 18). Who or what constitutes "the human" or "the people" in question here? The project of human self-definition gains traction through intuition. Intuition plays a central role in any attempt to overcome or transcend consciousness, whether in religious, artistic, mysticist, or esoteric practices, or in contemporary scholarship on cognition and decision-making. Somehow, through intuition, we can allegedly heal ourselves or develop a more perfect, spiritual existence by way of integrating something else into our conscious being in the world. So too with humor: animals may cackle or laugh, but only Humans have humor. Aristotle's homo ridens still features heavily in introductions to humor theory. And lastly, of course, hardly any academic treatment of "play" can do without Turner's homo ludens, or Schiller's dictum that "man only plays when in the full meaning of the word he is a man, and he is only completely a man when he plays" (80). In this chapter, I look into the historical and discursive development of this universalized and universalizing Humanism. I lay out where our contemporary idea of modern Humanity comes from and how it hides its contingency and cultural specificity from white subjects by presenting itself as spiritually universal and objectively absolute. ${ }^{1}$

In "Unsettling the Coloniality of Being/Power/Truth/Freedom," Sylvia Wynter writes that our "varying ontogeny/sociogeny modes of being human, as inscri-

\footnotetext{
1 Note that, in this sentence, the referent-we functions generically, partaking in a discourse that creates the illusion of such genericity in the first instance. I maintain the use of we, us, or ourselves not to assume a shared positioning of myself and the reader, but to mark myself as within an episteme that cannot be transcended by the stroke of a hand. By doing so, I hope to mark my own position as an inhabitant of the world, in which "we" refers to the culturally specific realm of subjectivity. The "us" in this project is always culturally specific.
}

2 OpenAccess. (C) 2022 Michel Büch, published by De Gruyter. (cc) BY-NC-ND This work is licensed under the Creative Commons Attribution 4.0 International License. https://doi.org/10.1515/9783110752748-004 
bed in the terms of each culture's descriptive statement, will necessarily give rise to their respective modalities of adaptive truths-for, or epistemes, up to and including our contemporary own" (269). Any truth about humanity is never absolute but always a "truth-for," a cultural episteme emerging from a descriptive statement provided by a certain discourse around what it means to be human at a given time in a given place. Modern European imperial enterprises required a conceptual shift in what it meant to be human because the theocentric descriptive statements from the Middle Ages were challenged by colonial conquest. The medieval truths-for that defined human subjectivity as being a good Christian had to be modified to lend moral justification and political legitimacy to the expropriation of what was called the "New World" and the centuries of mass enslavement that have since defined modernity. Wynter argues with Aníbal Quijano that within the modern European political and military endeavors, "'the idea of race' would come to be the most efficient instrument of social domination invented in the last 500 years" (Wynter 263). However, the concepts of race and Blackness have not always been the signifiers for the social, epistemological, and political construct that I refer to as a "matrix slot of Otherness," in Wynter's phrase (266). In medieval times, the matrix slot of Otherness was applied to the enemies of Christ. The Christian subject, the Human before Humanism, was created in the image of God, and the infidel was its Other, "with Jews serving as the boundary-transgressive 'name of what is evil' figures, stigmatized as Christ-killing deicides" (Wynter 265-66). Whereas Christianity defined what it meant to be human in religious and theocentric terms, modernity introduced a descriptive statement on the grounds and in terms of rationality and politics. This is the emergence of Humanist Man1, as Wynter terms the political subject as the first variant of the modern Human. ${ }^{2}$

Wynter claims that this shift from the medieval Christian subject to the ratiopolitical Man of modernity did not involve a complete epistemological overthrow of the Christian dichotomy of Spirit/Flesh (in which the clergy stands at the top and the laity at the bottom). Rather it transumed ${ }^{3}$ this binary - a reformulation,

2 The numerical qualifier of Man1 serves later to differentiate this homo politicus from the later - biocentric - variant of the modern Human, Man2.

3 Wynter adopts this term from Harold Bloom, who notes that "cultural fields are kept in being by transumptive chains" (qtd. in Wynter 308). She mobilizes it to refer to a "carrying over" of tropes through different historical contexts in order to "keep the community going by means of its retroping of earlier tropes," quoting Bloom in "How We Mistook the Map for the Territory" (2016). In this project, I rely on it heavily as an argumentational tool, which I need not only to argue in historical diachronicity but transversally through different disciplines as well as linguis- 
both historically adaptive and culturally specific, of what the Middle Ages had discursively inherited from the descriptive statement of ancient Greek society. For the Greeks, the descriptive statement of what it meant to be human was mapped onto the physical cosmos, which served to create the illusion of "supernaturally (and, as such, extrahumanly) determined criteria” for human subjectivity: "this value distinction (sociogenic principle or master code of symbolic life and death) then being replicated at the level of intra-Greek society, in gendered terms, as between males, who were citizens, and women, who were their dependents" (Wynter 271-72). An assumed extra-human agency was understood to have organized the world in a specific way beyond human control. Even though this agency was constructed by the subjects of Greek society and only subsequently imposed upon the stars, for the subjects who lived within that order, this dichotomy was

the indispensable condition of their existence as such a society, as such people, as such a mode of being human [that] commanded obedience and necessitated the individual and collective behaviors by means of which each such order and its mode of being human were brought into existence, produced and stably reproduced. (271)

In understanding the arbitrariness of Greek self-description, we can better understand the contingency as opposed to the apparently "natural" or "God-given" status of our own. Such truths-for were never as universally absolute as they presented themselves to the subjects and the societies in question but always "remained adaptive truths-for” (271). Judeo-Christian Europe inherited the axiomatic Platonic postulate "of an eternal, 'divinized' cosmos as contrasted with the Earth, which was not only subject to change and corruption but was fixed and unmoving at the center" and reframed it in its specifically Christian terms. The theocentric statement of the Middle Ages was thus a transumption of the Hellenistic "master code" and similarly mapped the perfection/imperfection concept onto the heavens and the earth, only this time in its conception of the Adamic Fall as significant sin (271-72). Taking her cue from David Bohm - who in a 1987 interview points out that "each general notion of the world contains within it a specific idea of order," and that the specific order of the ancient Greeks was based on "the idea of an increasing perfection from the earth to the heavens" Wynter argues this idea of order was, by way of transumption or mapping, "Christianized within the terms of Judeo-Christianity's new 'descriptive statement"' of human being, based on its master code of the 'Redeemed Spirit' (as

tic and affective registers. Transumption, transuming, and transumptive are helpful terms for theorizing in a sphere where superficial decoding is often difficult to perform. 
actualized in the celibate clergy) and the 'Fallen Flesh' enslaved to the negative legacy of Adamic Original Sin, as actualized by laymen and women" ("Unsettling" 274).

However, the making of modernity following the Middle Ages was not as radical a revolution as is often suggested, but a smooth transition that was fully operational within the transumptive chain. While the new bourgeois king was no longer officially appointed by God but by the allegedly objective concept of rationality - and the political rationale of the modern West of course - modern Man as the subject of Humanism had to argue from within theocentric logic. The lay intelligentsia of modernity, finding "themselves in a situation in whose context, in order to be learned and accomplished scholars, they had had to be accomplices in the production of a 'politics of truth' that subordinated their own lay world and its perspective to that of the Church and of the clergy" (276), developed a Humanist concept within theological terms, creating a "hybridly religio-secular" version of Man that drew on the residue of the theocentric descriptive statement as well as the budding autonomy of the modern subject. Humanists successfully shifted away from the absolutism of the Church and its (previously condemned) earthly world by arguing that God had made Man in his model to admire him, and then left him "to decide for himself whether to fall to the level of beasts by giving in to his passions, or, through the use of his reason, to rise to the level of angels" (276-77). It was believed that, though responsible for its intelligent design, "He would have had to make it according to rational, nonarbitrary rules that could be knowable by the being that He had made it for" (278). This reformulation made it possible for a Human subject to emerge, Man1, which could be circumscribed without reference to Christian terminology as "the rational political subject of the state, as one who displayed his reason by primarily adhering to the laws of the state” (277). Reason and political law re-enforcing one another, the power no longer lay with the priest, but with the constitution; lawful behavior was substituted for piety. Existence was now conceptualized through a Humanist lens. A ratio-political descriptive statement superseded the theocentric one and, drawing on the transumptive chain, provided a new map for a preexistent discursive territory:

Spiritual perfection/imperfection, an idea of order centered on the Church, was now to be replaced by a new one based upon degrees of rational perfection/imperfection. And this was to be the new "idea of order" on whose basis the coloniality of being [...] was to be brought into existence as the foundational basis of modernity. (287-88)

Given the emergence of the modern matrix of discursive Human existence, what it meant to be human had to be re-negotiated terms different from theological 
compliance or conversion. ${ }^{4}$ No longer did "heretics [...] Enemies-of-Christ infidels and pagan-idolators" serve as "the physical referents of the conception of the Untrue Other to the True Christian Self.” The "matrix slot of Otherness" was vacant. There was yet no reassuring (b)order that defined what the Western European subject of modernity was not ("Unsettling” 265-67).

With the wisdom of hindsight, we must observe that modern Man did not realize the full potential of disposing with the theocentric descriptive statement. Hypothetically, this was a historical moment when human existence could have been rethought entirely without reliance on or recurrence to the dichotomies of Heaven and Earth, Christian and non-Christian, instead developing an idea of humanity that involved no fundamental ex negativo. However, because of the discursive logic grounded in the configuration of political power still held by Christianity, dehumanization and violence marked the beginnings of modernity: Man invented "race" as a solution to this crisis in self-definition to fill the matrix slot of Otherness. The construct of race "was therefore to be, in effect, the nonsupernatural but no less extrahuman ground [...] of the answer that the secularizing West would now give to the Heideggerian question as to the who, and the what we are" (264). Accordingly, race also answered the question as to who and what "we" are not: "the peoples of the militarily expropriated New World territories (i.e., Indians), as well as the enslaved peoples of Black Africa (i.e., Negroes)" (266). Humanism as a European or Western self-construction cannot be separated from the dehumanization of its colonized and enslaved Others, ${ }^{5}$ and Western modernity realized and actualized its new descriptive statement through colonialist and enslavist enterprises. In a "second wave of imperial ex-

4 Wynter elaborates this negotiation in detail in discussing the argument between Las Casas and Sepulveda:

a dispute that I will define as one between two descriptive statements of the human: one for which the expansion of the Spanish state was envisaged as a function of the Christian evangelizing mission, the Other [sic] for which the latter mission was seen as a function of the imperial expansion of the state; a dispute, then between the theocentric conception of the human, Christian, and the new humanist and ratiocentric conception of the human, Man2 [sic, probably Man1] (i.e., as homo politicus, or the political subject of the state). (269)

5 The concepts of Others or Othering, as I understand them, are part of a register of relationality that does not hold up in contemporary usage when we move towards anti-Black, abjective modernity, as I will show. I retain the term here to stay with the language of Wynter and work with her conception of the matrix slot of Otherness. She mobilizes this phrase to conceive of a specific Black Other that is so absolute and ultimate in its dehumanized (and abject) existence that relationality ultimately no longer applies. I also find the term useful to mark that modernity's creation of and reliance on anti-Blackness is culturally specific, even in the radicalness of this specific Other's manifestation. 
pansion," the West further transumed Man1 in biological, Darwinian terms as Man2 (266). This time "it was to be the peoples of Black African descent who would be constructed as the ultimate referent of the 'racially inferior' Human Other" as the "negation of the generic 'normal humanness,' ostensibly expressed by and embodied in the peoples of the West" (266). Among various Others such as the Savage, the most salient "was to be that of the mythology of the Black Other of sub-Saharan Africans (and their Diaspora descendants)," whose systemic stigmatization, social inferiorization, and dynamically produced material deprivation served to "verify' the overrepresentation of Man as if it were the human" (267). Drawing on the Ancient dualism of heaven and earth, this was "done in a lawlike manner through the systemic stigmatization of the Earth in terms of its being made of a 'vile and base matter,' a matter ontologically different from that which attested to the perfection of the heaven" ("Unsettling” 267). Blackness was constructed as the ultimate and absolute Otherness of Humanity. What differentiates the modern descriptive statement from the previous one was the radical way in which Man construed himself as universally true and objectively absolute:

\footnotetext{
While, as Christians, Westerners could see other peoples as also having gods (even if, for them, necessarily "false" ones as contrasted with their "true" and single One), as subjects defined by the identity Man, this could no longer be the case. Seeing that once its "descriptive statement" had been instituted as the only, universally applicable mode of being human, they would remain unable from then on until today, of [...] conceiving an Other to what they call human. (299)
}

The result, as Wynter proposes, was "that the new master code of the bourgeoisie and of its ethnoclass [biocentric] conception of the human [as Man2] was now to be mapped and anchored on the only available 'objective set of facts' that remained," namely "the set of environmentally, climatically determined phenotypical differences between human hereditary variations” (315). Because God was no longer understood to be in charge of societal order, that order had to be scientifically observed and then performatively actualized. Supernatural causation was substituted for natural causation, which was used to legitimize and justify mass enslavements and genocides (304). The belief in objectivity and the development of the physical sciences served perfectly to "make opaque to themselves/ ourselves [...] the empirical fact of our ongoing production and reproduction of our order, of its genre of being human, its mode of consciousness or mind, and therefore of the latter's adaptive truth-for" (307). Wynter here builds on Godelier's analysis of the "mechanisms that function to project their/our authorship [of the order we live in] onto Imaginary supernatural Beings" or their transumption. As in Ancient Greece, an observed reality is rendered abstract as the 
ostensible realization of a higher ontological order. The active maintenance of the matrix slot of Otherness still serves to veil "our own authorship and agency" of and in today's white, modern order (“Unsettling” 315). It allows us, as white subjects of that modern order, to construct ourselves as normal Humans with a perceived phenotypical difference from those who do not have the capacity for this same subjectivity. With Darwin, this discursive matrix gave rise to another manifestation of the subject-making dichotomy: those selected and those dysselected. The Darwinian, naturally selected Man2 is the manifestation of a culturally specific discursive design for the way in which white subjects articulate "biological Blackness" through the registers of cultural ascription or in economic terms. We are now in a space where our belief in naturally given criteria and their objective categorization makes it almost impossible to conceive of the fact that this is merely a culturally specific descriptive statement. Who wants to argue with such facts?

The killing of God's creation - a paradoxical act in Christian terms - became possible through the shift towards the ratiocentric Human. The matrix slot of Otherness was still the same slot for the same people because the referent of normalcy was its European same: "the Elect category of those redeemed from [...] sin has now been recast in terms of the 'by-nature difference' of rationality” (304). Within European imperialism, Black enslavement and genocides kept morality intact while simultaneously and reciprocally demanding from the white, modern subject a psycho-epistemological strategy that allowed its actions to align with Humanism. Our contemporary descriptive framework of biocentric Man2 (as transumed from the political subject Man1 as transumed from the Christian subject) is necessarily still "inscribed within the framework of a specific secularizing reformulation of that matrix Judeo-Christian Grand Narrative" (318) - and antiBlackness is the governing structural ground within that preexistent matrix. Race, then, must be understood as a structuring principle and not a feature or avenue for discrimination. Rather than a ground for negative stereotypes, race "was and is fundamentally the issue of the genre of the [modern] human" ("Unsettling" 288). It is impossible to disentangle whatever is formulated within the Humanist matrix from its anti-Blackness, because anti-Blackness provides the negation of the subject within the logic of that originary dichotomy. Without recognizing the function of anti-Blackness, we can make no sense of the Human as we know it today. While still largely ignored in mainstream cultural (or other) studies, this is consequential for the Humanities at large. Anything done in the name of Humanism, any discipline that focuses on the Human, any object (or its study) that mobilizes Humanist ideas is always already inseparably bound up with the racialization and dehumanization of Blackness and those 
whom the discourse marks as such. Wherever "the Human" is mobilized and built upon as a given, sensitive scrutiny is required.

\section{Being human in bios-mythoi hybridity}

I hinted above that when modernity transumed the theocentric descriptive statement of the human from the medieval Spirit/Flesh dichotomy, the Christian subject could have been overthrown completely if being-human-in-dichotomy had been called into question. If the subject could be thought outside of such a dualist (or binary) matrix, being human could create subjects that need no Other to make themselves, as Wynter suggests in her early essay "Ethno or Socio Poetics" (85). This would demarcate an actual rupture of the transumptive chain, and demand that we think about human being in an entirely different framework. It would need an axiomatic ground in which human being is neither static nor separated into categories like Spirit/Flesh (Christian subject), rational/irrational (political Man1) or selected/dysselected (biological Man2). Wynter has set out to develop such a conception. In "Toward the Sociogenic Principle," she takes a cue from Fanon's postulate that "[a]longside phylogeny and ontogeny, there is also sociogeny" (Fanon 4). The sociogenic principle is central in Wynter's critique of "our present culture's purely biological definition of what it is to be, and therefore of what it is like to be, human" ("Principle” 31). Fanon's sociogeny builds on Freud, who took the terms ontogeny (the study of an organism) and phylogeny (the study of a species) from Ernst Häckel's recapitulation theory (“ontogeny recapitulates phylogeny"), which assumed that an individual organism undergoes the same evolutionary phases as its species. Häckel was one of the first to conceive of politics as applied biology. He was a forerunner of eugenics and was enthusiastically received in Nazi Germany; Freud draws on this background when he conceptualizes the terms ontogeny and phylogeny for psychoanalysis. Introducing sociogeny, Fanon disposes of the naturalized, racial essentialism previously inscribed in the ontogeny-phylogeny relationship as developed by Häckel and Freud, while maintaining the axiom that the individual lives and exists by and through the species. Fanon rids the concepts of their "natural" and materialist determination while acknowledging the role of physiology of the human organism. With Fanon, we can think of the individual human body as a physiological entity that is nonetheless actually and effectively (in)formed by "a symbolic register, consisting of discourse, language, culture, and so on," which "accompanies the genetic dimension of human action" (Wehelye 25). For Wynter, as Alexander Wehelye notes, this provides a way to think being human in a space "where culture and biology are not only not opposed to 
each other but in which their chemistry discharges mutually beneficial insights" (25). Sociogeny provides a sphere to theorize being human as a praxis departing from the level of the socially performative. It offers an entirely different conception of what it means to be human, one that directly addresses the human body in its biochemical existence without resorting to determinist materialism or giving in to semiotic or performative musing. Sociogeny involves an entirely novel conception of being human.

Wynter elaborates in various essays and interviews on her idea that "the human is, meta-Darwinianly, a hybrid being, both bios and logos (or, as I have recently come to redefine it, bios and mythoi" ("Catastrophe" 16). She always makes clear that "should this hypothesis prove to be true, our system of knowledge as we have it now, goes.” The transumptive chain discussed above, which has always forced theorizers to ground human subjectivity discursively on the master codes of Spirit/Fallen Flesh, would be massively disrupted. The entire system of our understanding of the world, and of ourselves, would break apart: "If human beings are conceptualized as hybrid beings, you can no longer classify human individuals as well as human groups, as naturally selected (i.e., eugenic) and naturally dysselected (i.e., dysgenic) beings. This goes away. It is no longer meaningful" (17). Wynter suggests that we, as homo narrans, as being human in bios/mythoi hybridity, came into existence by way of a Third Event:

The First and Second Events are the origin of the universe and the explosion of all forms of biological life, respectively. I identify the Third Event in Fanonian-adapted terms as the origin of the human as a hybrid-auto-instituting-language-storytelling species: bios/mythoi. The Third Event is defined by the singularity of the co-evolution of the human brain with - and, unlike those of all the other primates, with it alone - the emergent faculties of language, storytelling. This co-evolution must be understood concomitantly with the uniquely mythmaking region of the human brain, as the brain scientists Andrew Newberg, Eugene D’Aquili and Vince Rause document. (“Catastrophe” 25)

Locating her conceptualization of being human in the discipline and language of neuroscience, she defines the sociogenic principle as

the information-encoding organizational principle of each culture's criterion of being/nonbeing, that functions to artificially activate the neurochemistry of the reward and punishment pathway, doing so in the terms needed to institute human subjects as culture-specific and thereby verbally defined, if physiologically implemented mode of being and sense of self. ("Principle" 54)

Because the symbolic triggers for affective procedures that "activate the neurochemistry" are artificial, there is one central consequence: "humanness is no longer a noun. Being human is a praxis" (“Catastrophe” 23). If we had other criteria 
instead of the dichotomies of the transumptive chain that result in the matrix slot of absolute Black Otherness, our brains would look different, would be activated by different triggers. We would feel different, experience the world in entirely different and yet unimaginable modalities. Being human, then, is a continual act of reasserting the bodily integrity of our sense of self, which is symbolic nonetheless. The simultaneity of bios and mythoi (not opposed to but along with each other) in being human-as-praxis is the theoretical sphere in which this project is located.

\section{Psychoanalysis as embodied cognition}

Though starting from Fanon, Wynter's conception departs from his in that she is not interested in psychoanalysis or any of its tools. Instead, she frames her bios/ mythoi concept not only as decidedly meta-Darwinian but also meta-Freudian ("Catastrophe" 54). As I build largely on Wynter, why would I mobilize the psychoanalytic toolkit? I find it methodologically helpful because, ultimately, this project needs a language that communicates with the discourse. This is not a self-aggrandizing attempt to further advance or develop Wynter's theorization of being human, and so I seek to work from her axioms while drawing on a conceptual framework with which I can immediately address the fields in question: intuition, play, and humor as realized in improv. This also helps to frame Broeck's notion of anti-Black abjection in the culturally specific libidinal economy of white modernity as the praxis of maintaining the white modern subject qua the continual abjection of Blackness - that is, the dehumanization of any body, object, or phenomenon racialized as Black. This in turn resonates strongly with Wynter's definition of the sociogenic principle as presented above, even though articulated in the language of psychoanalysis. The psychoanalytic concepts I apply always remain tethered to original and contemporary findings and positions developed in embodied cognition theory, which Wynter also uses to ground her theory. Currently, and despite the celebration of affect theory, the disciplines and languages of psychoanalysis and embodied cognition do not regularly communicate as productively as they could. Indeed, thinking psychoanalysis alongside embodied cognition runs the risk of getting ground up between the ideologies of the black box ${ }^{6}$ of the unconscious, and that of an elim-

6 Among the many phrases in which common usage of the adjective black manifests white modern racialized knowledge - for example, "black humor" being concerned with sexuality or death, and "blacking out" denoting a loss of consciousness and the reduction to automatic bodily functions - black box is particularly telling, because we can only see the outside or the sur- 
inative materialism. While cultural studies scholars are starting to speculate on the potential of their integration, representatives of the respective disciplines do not have much to say to each other. Consider cognitive scientist Guy Claxton, who addresses the interdisciplinary relationship directly in Intelligence in the Flesh:

At my most radical, I would now claim that, not only are "the gods and spirits" non-existent (even though they may still have their uses), but the unconscious is dead too. We may choose to continue using it as a metaphorical or poetic way of talking but there ain't no such animal. There are myriad processes in the body that never lead to conscious experience, but there is no real, identifiable place or agent inside us that is a separate source of impetus from consciousness and reason. Like "the mind," "the unconscious" is a place-saver, a dummy explanation. It is like a temporary filling in a tooth, put there till something better comes along. And now it has. (12)

But has it? Freud may well have subscribed to this. The adoption of terms like ontogeny or phylogeny from biology speaks to the way in which he framed his theorizations as natural science. In "The claims of psycho-analysis to scientific interest," he articulates the relevance of psychoanalysis for various disciplines, including biology and the language sciences, which, if properly framed, would make psychoanalysis an apt instrument for the study of being human as bios/ mythoi. In "Beyond the Pleasure Principle," Freud speculates about a "specific locus" for consciousness by "aligning ourselves with the locational hypotheses of cerebral anatomy” (64). Kathryn Armistead speaks for many scholars critical of this version of Freud, who "[w]herever possible [...] substantiated his conclusions using arguments based on physical, biological reality." She understands these as strategic gestures to ensure "his own place in the history" at a time when the natural sciences were in the march (2). Be that as it may, there is something to be recognized in the relationship of early psychoanalysis with the natural science of what would later be called cognitive science. For Freud, "the mind, whether conceived of as conscious/unconscious or ego/superego/id was always a product of the brain," which relates to contemporary theories of embodied cognition and their questions about consciousness. If Freud was convinced that when therapists and patients unearthed "mental artifacts" in the analytic process, this would cause a "material difference in the patient" that also relates to cognitive science (Armistead 2). If nothing else, this does give us a cue to go onward.

face of that box. We can control what goes in, and we can see what comes out. But what goes on in there in empirical actuality, white modern science has given up on knowing. 
In this project, I attempt to think embodied cognition and psychoanalysis together, each informing the other, seeking to develop an understanding of some select concepts that ultimately feed back into one another. As suggested by Claxton, I will use the language of psychoanalysis as a "place-saver" or "dummy explanation" for what goes on in the body. However, I do so not in ignorance of the idea that "something better has come along," but because cognitive science only does half the trick when it comes to the conception of being human per Wynterian bios/mythoi hybridity. Working in a psychoanalytic framework and applying the language of an unconscious structured like a language, as suggested by Lacan, does not at all necessitate the disposal of an individual organism's biochemistry. The latter feeds into and substantializes the former, and the former can help us to talk about and interpret the latter. ${ }^{7}$ And while neuroscience helps us to realize and observe the mechanics, the psychoanalytic instrumentarium can do what it does best: labor at developing a language for an object that is absent. A language for something that only shows itself in its effects but not in its ontology - because it has none. The psychoanalytic object of study is something that by definition we cannot know, but which provides meaning to what we are and do. Neuroscience cannot do that. Not only do I think it is valuable to keep working with psychoanalytic concepts "as a convenient shorthand for talking about complex human processes and experiences" alongside the evidence put forward by experiments of and for embodied cognition to rethink being human in Wynter's vein (Claxton 139). I also build from Claxton's admission that "[s]ome of what is interesting about us humans can be well talked-

7 Lyotard's Libidinal Economy suggests this perspective as well by mobilizing the body as both metaphor and actual space for the goings-on of what Freud conceived of as libidinal economy. The book opens with a vivid and literal "opening" of a body, involving all biological matter imaginable, then develops the metaphor into the Moebius strip on which linguistic representation takes place, in the "theatrical volume," which then provides the language and framework for the libidinal economy. In this way, Lyotard can conceive of libidinal economy as being one with the actual body:

Don't forget to add to the tongue and all the pieces of the vocal apparatus, all the sounds of which they are capable, and moreover, the whole selective network of sounds, that is, the phonological system, for this too belongs to the libidinal "body," like colours that must be added to retinas, like certain particles to the epidermis, like some particularly favoured smells to the nasal cavities, like preferred words and syntaxes to the mouths which utter them and to the hands which write them. (2)

With Lyotard, we can say that "libidinal economy" is a way to conceptualize the body as the primary locus not only of hunger, thirst, and digestion, but also of feeling, thinking, imagining, and as matter that itself is capable of learning. This corresponds well with Wynter's demand for the recognition of being human as a bios/mythoi hybrid praxis, thinking the symbolic and the biological alongside each other. 
about in body terms, while other aspects are handled more elegantly by mind language" (140). Some aspects of being human will come to the fore in one discipline, others in the other, and some precisely in the space between, opened up by psychoanalyst Fanon's conception of sociogeny.

\subsection{The modern libidinal praxis of anti-Black abjection}

\section{Libidinal economy of Black enslavement}

In Red, White \& Black, Frank Wilderson propagates a "radical return to Fanon." Unlike Wynter, however, he elaborates on Fanon's psychoanalytical dimension, taking into view the "libidinal economy of civil society" that structures and drives the psychosociality of white modernity (15). He defines it with Jared Sexton as "the economy, or distribution and arrangement, of desire and identification (their condensation and displacement), and the complex relationship between sexuality and the unconscious" (qtd. in Wilderson, Red 49). Building on Orlando Patterson, who defines the social ontology of enslaved people as one of social death, Wilderson argues that slavery in modernity has become "the singular purview of the Black," who has been "socially dead in relation to the rest of the world" ever since. Where in Patterson's work enslavement is understood as "a condition that anyone can be subjected to" (18), for Wilderson "slavery is and connotes an ontological status for Blackness" (14), providing the only "access to (or, more correctly, banishment from) ontology" for those racialized as Black. They are thus "by definition always already void of relationality" (18). The primary function of the construction of Blackness is, as Wilderson argues, symbolic rather than economic. He follows Eltis in assuming that it would have been much more profitable to seize "convicts, prisoners and vagrants" from Europe, rather than taking up the financial effort of sailing to Africa (15). Granting that "the constituent elements of slavery are not exploitation and alienation [as Patterson suggests], but accumulation and fungibility (as Hartman puts it): the condition of being owned and traded" (Wilderson 14), the enslavement of white people was unthinkable for white people. Enslaving a fellow white subject, even if they might have had a life sentence in prison, would have "stripped the convict of the aura of the social contract" (15). Such social autoaggression or autodestruction was unimaginable because it would have challenged the antiBlack system at large. Wilderson writes that in an imagined process of whiteon-white enslavement, "[w]hat Whites would have gained in economic value, they would have lost in symbolic value; and it is the latter which structures the libidinal economy of civil society" (15). Further, if people racialized as 
Black were understood as agents with cognitive, rational powers, like their white counterparts, the absence of legitimation of their subjection would be overt:

The race of Humanism (White, Asian, South Asian, and Arab) could not have produced itself without the simultaneous production of that walking destruction which became known as the Black. Put another way, through chattel slavery the world gave birth and coherence to both its joys of domesticity and to its struggles of political discontent; and with these joys and struggles the Human was born, but not before it murdered the Black, forging a symbiosis between the political ontology of Humanity and the social death of Blacks. (Wilderson $20-21)$

Blackness served as the referential background of the semiotic chaos, against which free Europeans could cut out their own image of civilized subjectivity both in discursive and affective terms.

I state this explicitly because I suggest that Wilderson's theorization of the anti-Black libidinal economy can and should be related to Wynter's concept of the matrix slot of Otherness. I am aware that the term "Other" can be understood as implying relationality, which - speaking with Wilderson - never encompasses Blackness. Yet I read Wynter's understanding of Man in its absolute universalization of the white self in that very non-relation to Blackness as developed by Wilderson. As mentioned above, modernity brought about the culturally specific transumption that there were, in fact, no Others to the white subject of Man, "overrepresented as the generic, ostensibly supracultural human" (288); for the biocentrically described Man2, Blackness served as the "missing link" connecting "true (because rational) humans and the irrational figure of the ape" (Wynter, “Unsettling” 304). This allegedly naturally determined existence outside Humanity has no relationality, no discursive potential for political subjectivity or political ontology, to use Wilderson's term. Similarly, Wilderson emphasizes the libidinal dependence of whiteness on the existence and active maintenance of Blackness. Just as Hobbes could not articulate his concept of individual subjectivity in terms of self-possession without imagining bodies lacking such self-possession, there can be no freedom without relation to the most naturally unfree, which is the figure of the Black: "Without the Negro, capacity itself is incoherent, uncertain at best even” (Wilderson, Red 15). Anti-Blackness is the ground on which possibility itself can be played out on any kind of sociopolitical grid - which does not imply that every position is of power, but that every position is of potential power. Resonating with Wynter, Wilderson applies the term "matrix" to address the existential dependence of white subjective existence on the social death of Black-racialized people: 
Whiteness is parasitic because it monumentalizes its subjective capacity, its lush cartography, in direct proportion to the wasteland of Black incapacity. We should think of it as a kind of facility or matrix, through which possibility itself can be elaborated. (Red 45)

I suggest, then, that with Wilderson we can libidinalize Wynter's notion of the matrix slot of non-Human Otherness as a sphere of Blackness that denotes non-capacity, non-being, and non-Humanity. It is a space flexible enough to incorporate every non- required by any given time or place. The (hypothetical) recognition of Black capacity or agency would require the complete disintegration of current formations of sociality because the entire affective grammar through which the white modern subject knows itself would lose its grip. There is no alternative to the stably reproducible "physiologically implemented mode of being and sense of self," as Wynter writes in her definition of the sociogenic principle ("Principle" 54).

It must be understood that Blackness is not a by-product of white subjectmaking but the foundational structure of the universalized white self of modernity for whom it is otherwise impossible to self-conceptualize "ex positivo." Given the modern descriptive statement as its discursive prefiguration, the white subject relies on Blackness ex negativo and on the continual performance of antiBlackness, because "with being human everything is praxis” (Wynter, "Catastrophe” 34). In what follows, I elaborate on the notion of anti-Black abjection developed by Broeck as the praxis central to the making of the modern white subject. I read anti-Black abjection as a culturally specific practice performed and observed on many levels, including its visceral and neurochemical hardwiring. I hope to formulate some of the dimensions of this praxis across all aspects of white existence, from actions to perceptions, from political actions to musical tastes. I will focus on the libidinal ground, which I posit as the primary motivational force for all things white as expressed in myriad cultural and artistic practices.

\section{Abjection with Broeck and Kristeva}

Broeck coins the phrase "white Euro-American abjectorship" ("Legacies” 109), reading abjection "in the post-Fanonian vein in which it appears in Saidiya Hartman's and Hortense Spiller[s]'s work [as] a theoretical concept to discuss the underside of white Western modernity's terms of human sociability and subjectivity" (Gender 13). Departing from Kristeva's treatment of the psychoanalytic concept, Broeck does not concern herself with a phenomenology of the abject in its alleged irreducibility or its potential to disturb the symbolic order but mo- 
bilizes its predicative performance of white subject-making grounded in the dehumanizing practice of enslavement. She writes:

It is important to stress, though, that, while I am borrowing from Kristeva's notion of the abject as that which threatens the subject's secure anchoring in the symbolic from an elsewhere, I am in contradiction to Kristeva. I am not interested in her question of what the abject does to an individual or collective subject - plunge it into states of disorientation but in the way in which the white modern subject (male and female) might be considered an abjector, that is, a motorizing force which needed Black thingification to "know" socially, culturally, politically and epistemically, its subjectivity and social being. (Gender 17)

Broeck thus mobilizes the term with Hartman "to be able to talk about the positioning of human beings as female flesh, as that abject which has been most radically beyond the pale of the subject in an Enlightenment vision" (Gender 13), as a performative action that ensures the "bounded bodily integrity of whiteness secured by the abjection of others" (Hartman, Scenes 123). This historicized usage of the term is helpful to discuss what up until today "has been structurally, not contingently, cut off from the human, from the self-possessed possessor of the world and its things" (Gender 13). White abjectorship for Broeck describes a system and the predicative transitivity of white subject-making that encompasses both internal (as a psychic, self-making principle) and external (directed against others) activity. In a systemically anti-Black abjective structure, a white body attains subject status qua acts of outward anti-Black abjection and can also experience psychophysiological sensations of inward acts, as I suggest below. ${ }^{8}$ In the modern system of white abjectorship, subjectivity without anti-Black abjection is inconceivable. There is no white subject who is not an active anti-Black abjector, because we can neither escape a) the transumptive chain that prefigures us to conceive of ourselves in descriptive statements based on dichotomies, nor b) the cultural specificity of our present descriptive statement, which is semantically realized through anti-Blackness. In this inward libidinal process, the psychic space of "Blackness" is created, a space without limits that cannot be determined positively. White abjectorship thus denotes the (mode of) doing whiteness qua culturally specific anti-Black abjection, creating a boundless sphere of the white non-: non-subjectivity, non-sociability, non-being. This discursive nonspace is central to the sociogeny of the modern West, informing its phylogeny and ontogenies. Individual performances of anti-Black abjection correspond to the continual performative making of white sociability as such, which according-

8 The notion of anti-Black abjection through "inward acts" likely stretches Broeck's use of the term. 
ly holds subjective capacity for whites only. In order for the system of white abjectorship to work, any body, object, or phenomenon cast (off) as "Black" is treated in the same predicative manner as non-relation to the reigning subject as a visible performance of white abjectorship.

Where for Kristeva the subject is "beset by abjection" (2, emphasis mine), Broeck deploys the concept as something done rather than experienced. She conceives of the abjective process as an action grounded in the psychic social and individual anti-Black structure described above. Anti-Black abjection thus describes not only a systemic order of the modern West but also its repeated reinstatement, its continually performed actualization in the real world, the singular acts and performances enabled by and performed for the anti-Black systemic order. Through anti-Black abjection-as-action, the white subject reinstalls itself when- and wherever necessary - or simply because it has the capacity to do so in a leisurely pursuit of jouissance. What can be gained from this reconsideration of Kristeva? First, given the libidinal dimension of anti-Black abjection in Broeck's and Hartman's use of the term, a return to Kristeva can indeed offer insight because culturally specific semantics are always read along and mapped onto her argument. When read through the culturally specific and systemic anti-Black actualizations of abjection, many of the terms and phrases in her detailed description of abjection reveal how naturalized concepts like disgust must be understood within the anti-Black discursive matrix. Reading Broeck alongside Kristeva is thus metatheoretically relevant. Second, I find a small conceptual treasure in Kristeva's essay, which - at least by way of analogy - resonates with other concepts in the psychoanalytic toolkit I draw on in discussing intuition, play, and humor. This immediate connectivity is worth maintaining, as long as we keep cultural specificity in mind and are never seduced by a universalized assumption of generic humanity. This gesture is inspired by Mills's argument for a mobilization of "contract talk" to elaborate on white supremacy, suggesting that the idea of a Racial Contract is "one possible way of making this connection with mainstream theory, since it uses the vocabulary and apparatus already developed for contractarianism to map this unacknowledged system" (Contract 3). To draw on Kristeva's psychoanalytic classic has its advantages, even though the self-propelling logic of "unconscious talk" must at times be tethered to the cultural specificity and actual cultural phenomenon in question. Subsequently, I will mobilize concepts of embodied cognition to suggest we can understand antiBlack abjection as a definable somatic state that provides us white subjects with a very special jouissance of revamped symbolic and bodily integrity. In doing so, I hope to contribute to a "thick description" that "understand[s] the intricate psychic, social, and intellectual mechanics of European modernity's culture of self as ownership, the mechanics of abjectorship" (Broeck, "Legacies" 121). 


\section{Jouissance of "I"}

Kristeva defines abjection as an instinctive and pre-conscious physical reaction against that which is "improper/unclean" (2). In this sense, it is already linked to the matrix slot of Otherness, to the sphere of non-homogeneity of the Earth rather than the high reason of the Heavens. Most pronouncedly, subjects experience the abject when confronted with the fleshliness of the individual body, as when we find ourselves in the presence of a corpse. For Kristeva, the corpse, "seen without God and outside of science, is the utmost of abjection. It is death infecting life" (4). In the symbolic and actual dichotomy of life/death, death is existentially constitutive of life: "refuse and corpses show me what I permanently thrust aside in order to live. These body fluids, this defilement, this shit are what life withstands, hardly and with difficulty, on the part of death. There I am at the border of my condition as a living being" (3). If a human cadaver (from Latin "cadere:" to fall) is the ur-abject, we can see how it features and functions in the theocentric descriptive statement of the Middle Ages in the dichotomy of Spirit/Fallen Flesh, filling the matrix slot of Otherness with the non-believing sinner - metaphorically the original sin, the Adamic Fall from the grace of God. In the theocentric terms of Christianity, however, abjection still encounters "a dialectic elaboration, as it becomes integrated in the Christian Word as a threatening otherness - but always nameable, always totalizable" as sin (17). Transuming the descriptive statement of what it means to be human into modernity, the totalizable Sin, the Flesh fallen to the "nonhomogenous nadir of the earth" (Wynter, "Unsettling" 274), the matrix slot of (absolute and non-Human, non-living) Otherness becomes the sphere of Blackness, which we must understand as a praxis: as whatever white modern subjects do. While we can maintain the dead fleshliness of the corpse as Kristeva's ur-abject, we must also acknowledge that actual and symbolical death as well as the human-as-flesh has been cast (off) by the racializing theater ${ }^{9}$ of modernity as Blackness in order to create its

9 Applying this grammar and lexicality, Lyotard's notion of the theatrical volume comes to mind, which Ashley Woodward describes as follows:

Lyotard explains the relation between libido-desire and wish-desire with the figures of the libidinal band and the theatrical volume. In itself, libido operates according to the primary processes (the unconscious), which knows nothing of negation, space or time. This is envisaged as the libidinal band, a Möbius strip (without inside or outside), along which intensities run at infinite speed, such that their position cannot be localized in time or space. Wish-desire is described according to the slowing, folding, and hollowing out of the libidinal band to form a "theatrical volume." This describes wish-desire as a function of representation: that which is lacked is represented on the stage, while the real thing lies outside the theatre walls. The theatre also describes the secondary psychical processes: 
subjects qua sociogeny. From here on, we can no longer merely hypothetically (and pointlessly) conceive of abjection beyond Blackness, but must read it today (corresponding to Wynter's notion of a "truth-for") in its modern, culturally specific actualization as an abject-for white subjectivity. The abjective act of modern white subjecthood must be framed by way of its culturally specific actualization as anti-Black by definition.

Importantly, the abjective act is the specific point at which the subject enters language and an "I" can be experienced, uttered, come to exist. In a psychoanalytic framework, this corresponds to the moment of severing the child from the nurturing breast of the mother and the introduction of a symbolic system: "There is language instead of the good breast" (Kristeva 45). By way of abjection, we create the first differential split into me/not-me as the ur-sensation of entering the sphere of this/not-this, of signification at large. It follows that whatever is discursively and affectively mapped onto the experience of not-me denotes the sphere of unintelligibility, which is both the ground for and a threat to signification in the actual, historically contingent, culturally specific subject-making system through which it is articulated. Phobic objects emerging from the abject sphere are thus prefigured (and cathected) by the cultural specificity of what it means to be human, and will always stand for a "hallucination of nothing," turning into a "metaphor that is the anaphora of nothing" and might pose a threat to the discursive system (42). Accordingly, with sociogeny in mind, we can understand how the continual praxis of anti-Black abjection is crucial for the maintenance of modern subjectivity. Given that the (active) psychic, visceral, and cognitive experience of abjection establishes the first not-me and thus creates the experience of $I$, and that "I abject myself within the same motion through which 'I' claim to establish myself" (3), the modern West is hopelessly dependent on the continual abjection of Blackness to maintain what has originally been established as $I$, that is, as the subject of its social order. Anti-Black abjection, then, lies at the border of symbolic modern being in the world. White subjectivity relies on the continual, structurally prescribed praxis of anti-Black abjection to generate, organize, and perform social signification as such. Without anti-Black abjection, the modern subject would be like Kristeva's "child, who has swallowed up his parents too soon, who frightens himself on that account, 'all by himself,", whose fear "permeates all words of the language with non-existence" (6). The powers of horror become the powers of Blackness. Kristeva considers the "limit that turns the

space, time, the concept of language, all of which depend on the basic distinction (this/not this) absent from the libidinal band. (128) 
speaking being into a separate being who utters only by separating - from within the discreteness of the phonemic chain up to and including logical and ideological constructs." She then asks: "How does such a limit become established without changing into a prison" (46)? This prison, or "fortified castle" (47), describes a hypothetical state - real only for the borderline patient - in which the subject/ object relation has lost all connection to the abject and consequently to itself, having originated in abjection. There is only pure signification, pure structure, "pure and simple splitting, an abyss without any possible means of conveyance between the two edges" (47). Kristeva casts abjection as preventing such "petrification" because it lets "current flow into such a 'fortified castle."” As a result, a "subject-effect - fleeting, fragile, but authentic - allows itself to be heard in the advent of that interspace, which is abjection" (48). Such a subject-effect is driven by jouissance, which lies in experiencing oneself as both prior to and having mastered the initial abjection of separation from the mother.

Kristeva differentiates a generalized and “ostensibly supracultural” (Wynter, "Unsettling” 288) human existence from beasts by way of our capacity to abject, as the initiation into the symbolic (and exclusively Human) realm: "The abject confronts us [...] with those fragile states where man strays on the territories of the animal" (12). There is quite a lot to unpack in this assertion. First, we need to observe (meta-theoretically) that Kristeva draws on the distinction between the rational Human being and the "territory of the animal" as a pre-civilized state of nature. This very distinction can function only within the dichotomy that creates Man2, the biocentric Darwinian conception of being human, itself already racialized. If, for the abjector, the territory of the animal is a "fragile" state, this means that the abjector distinguishes themselves from a "natural" state of being they (allegedly) once inhabited. The racial ascription is, of course, that the Black body still inhabits this space, which means that abjection is a praxis for which a Black-racialized body has no capacity. Kristeva's universalized approach has a colossal Black spot. Moreover, this "fragile" state of abjection, walking the limits of Humanity as it were, speaks to an existential, narcissistic, and solipsist crisis that leads nonetheless to the jouissance of the "subject-effect:"

[The abject] takes the ego back to its source on the abominable limits from which, in order to be, the ego has broken away - it assigns it a source in the non-ego, drive and death. Abjection is resurrection that has gone through death (of the ego). It is an alchemy that transforms the death drive into a start of life, of new significance. (Kristeva 15)

Relating the joyful subject-effect of abjection as an "alchemical” procedure to culturally specific anti-Black abjection, we can make sense of innumerable 
white actions otherwise difficult to comprehend (and I consider several of them later). For Kristeva, the jouissance of the "subject-effect" transcends superficial concepts of fear or desire: "jouissance alone causes the abject to exist as such. One does not know it, one does not desire it, one joys in it" (9). This is in part why it is so difficult to grasp: the subject may experience jouissance in the perception of Blackness or in the performance of anti-Black abjection - voluntarily or involuntarily - without recognizing the racial structure that underlies it. However, in actuality, the anti-Black subject-effect in white modern subjectbodies is achieved through the modalities of fear and want, fear being an "abortive metaphor of want" (35). Fear, in the first instance, denotes the "states of distress that are evoked for us [adults] by the child who makes himself heard but is incapable of making himself understood." It denotes a physical state right in the process of subject making, the "upsetting of a bio-drive balance" that is later articulated in symbolic terms through and repeated by the "constitution of object relation" (33). Being in the world as a subject can thus be described as "alternating with optimal but precarious states of balance" (34). Abjection ensures the maintenance or reinstallation of libidinal (and material) homeostasis in the Human organism. This "calls attention to a drive economy in want of an object that conglomerate of fear, deprivation and nameless frustration" (35). ${ }^{10}$ Kristeva states that "[p]hobia literally stages the instability of object relation" (43). For the white modern subject, the foundational phobic or phobogenic object is the Black-racialized body (see also Hartman, Scenes 57; Fanon, Skin 82-108). Secondarily, this also accounts for other signs that signify Blackness. The most efficient way to actualize the white self and generate a subject-effect authentically (if fleetingly) is by sliding through the portal of abjective experience and delving into the sphere of Blackness. When Kristeva asks how the limits of relationality, of language and the subject/object splitting, can be prevented from becoming a

10 It must be noted that, though bearing "the mark of frailty of the subject's signifying system" (Kristeva 35), the phobic object does not come into being by way of substituting the father as the first order object of fear, and does not itself inhabit the sphere of relationality. For both Broeck and Kristeva, abjection provides the ground for object relations but has no access to the very space it enables. Speaking with Wilderson in the culturally specific terms of anti-Black modernity, the dehumanizing and abjective praxis of Black enslavement provides the only "access to (or, more correctly, banishment from) ontology" (Red 18). Broeck writes:

To come into being, the European subject needed its underside, as it were: the crucially integral but invisible part of the human has been his/her abject, created in the European mind by way of racialized thingification: the African enslaved, an un-humaned species tied by property rights to the emerging subject so tightly that they could - structurally speaking - never occupy the position of the dialectical Hegelian object as other, has thus remained therefore outside the dynamics of the human. ("Legacies" 118) 
prison, how the ego can experience itself as free, the culturally specific answer is: qua anti-Black abjection.

Where the religious codes for the signification of the abject within the structures of the theocentric super ego provide the concepts "defilement, taboo, or sin" (Kristeva 48), the modern matrix of being Human holds any signifier that denotes "Blackness" as the invigorating source for its white subject's self-making. Blackness is the current that flows in the object relation of white supremacy whenever needed, animating, resuscitating, and invigorating the system of white supremacy on all levels, in all groups and individuals to the extent that their libidinal economy functions according to (and is rewarded by) that system. White modern subjectivity reenacts and stabilizes white abjectorship as the primary mode of its specific sociogenic principle. It is qua specifically anti-Black abjection that the modern subject reenacts what Lacan calls the "unitary bent." By way of anti-Black abjection, we white subjects confront and remind ourselves of a maternal entity, even relive it (Kristeva 13). In our current system of existence, Blackness and all units and modes to which that signifier is attached functions as a sort of portal to the joyful experience of a subject-effect, whether triggered by fear or desire. The want for one's subjectivity overrides either. It cannot be stressed enough that this portal of Blackness is not a natural given but one that the culturally specific subject of white modernity (exclusively!) can open up any time and place. In the bios/mythoi hybridity of our existence, Blackness is located in the "languaging" sphere of mythoi (Wynter, "Catastrophe" 32), which structures, shapes, and informs our bios. Below, I aim to help develop a language for the specific procedures and practices of shaping or informing the human body as an affective biochemical configuration. First, however, I consider some of the dimensions in which anti-Black abjection happens.

\section{Modes of abjection}

I have suggested that anti-Black abjective practice, by whites for whites, is always already structurally directed against those racialized as Black. It can be an internal procedure or an externalized outward act - or both at the same time. Further, on the level of the anti-Black libidinal structure ingrained in politics, bodies, embodied psyches, and the sociopolitical sphere, I propose that we need not distinguish specific kinds of anti-Black abjection. Is the willful seeking out and consumption of a given film (and the associated support of the creation and production of such images) not also an act of abjection? Is the creation of a mental image (be it based on memory/imagination or actual perception) not an act in itself, especially given that embodied cognition teaches us that memories, per- 
ceptions, and imaginations function similarly in our bodies? Is a feeling not also an outward performance, for example in the microaggressions we as white subject-bodies send out as involuntary but perceptible facial expressions, sweat, or change of heart rate too minute to be easily detected? From what cranny in the body does a white subject derive pleasure in listening to Prince? What exactly does an audience enjoy in the Black Panther movie? Is it at all possible for a white audience to decode the affect of such a film in a meaningful way? What does the white collective audience-we do with, about, and to Spike Lee's Bamboozled? Accepting the polyvalence of abjection (as articulated in this series of questions) is consequential. Certainly the cop with his finger on the trigger at the sight of a Black man is not exactly like the auctioneer on the coffle, who is not exactly like an audience member of a minstrel show, who is not exactly like a blackface performer in that same show, but they are all part of the same sociogenic species, sharing the same discursive and affective DNA. Even though it may be a long way from a semi-ironic white fist bump to the Charleston church shooting, it is important to understand that there is an unbroken continuum, a shared axiomatic and affective ground of violence that connects the two.

Language is the plane on which we can analyze this continuum out in the open. The use of anti-Black abjective language finds its contemporary discursive nexus in the question of whether the use of the n-word by white people is or should be permitted, and if so, in what context(s) it might be permissible. The verve with which white people use (and rationally defend) their right or structural capacity to use the word - attained through the gratuitous and dehumanizing violence of modern Man - can only be understood in terms of psychic necessity, in the symbolic value that uttering and hearing, writing and reading it provides. As Lyotard writes in Libidinal Economy, there are some words that the mouth "prefers to utter" (2). The n-word is such a word for whites because its articulation (real or imagined) is in itself an act of anti-Black abjection that provides white subjects the joy of a subject-effect. It is one of the most effective pathways of modern sociogeny because it encapsulates white subjectivity in the entirety of its historical legacy. In the line of argument presented here, the n-word is the ultimate pathway for reasserting not only white superiority, but one's white existential subjectivity and subjective existence. Abjection is in action every time a white subject speaks, hears, imagines, writes, discusses, debates, defends, or even critiques the word.

Tellingly, the debate about using the n-word in improv (or the comedy industry at large) hardly ever addresses the question of its affective meaning and effects as considered in this project, once again using Blackness to ponder political notions of freedom of speech and artistic (or satirical) license. These feature largely in the discursive self-description of improv, but one central argument is 


\section{often put forward, namely the idea of "playing true to character," even if that spontaneously discovered character is racist:}

Perkins: People often use that to justify themselves. They think that because it's comedy, it gives you leeway to say whatever you want. But at the end of the day, we're two humans on stage making things up. You don't forget that you're a person. You can play a character, but that's what it is. It's a character. It's not you. You know what can and won't hurt your partner. Don't cross that line. I don't think that hurting another person is less important than the truth of a character. Once the scene is over, we have to live as people. First and foremost, when I am playing, I am thinking that nothing is ever that serious where I am not in a space with another person.

Bullock: You don't have to use that word to portray a racist character. I feel like the idea to "play the truth of my character" is a cop-out. Words mean things. Words have meanings. Once you say it, the whole scene has to be about that word. That's the kind of word it is. It has that kind of weight. So if you're bringing it into a scene, you better be prepared for that scene to be about that until the scene is done. If that's your point of view, that you can use that word to play "true to character," or even just to get a reaction, if you use it without foresight of what that word means, if you can't handle the context of that word or understand how it works in a room, then I'll be over here not doing that. If I hear that you use "playing true to your character" is your excuse, then I will blacklist you in my mind.

Perkins: Oh yeah. Definitely. (personal conversation)

Schleelein: I was discussing the matter of the n-word on stage with Rob Wilson last night.

Arashiba: Is Rob black?

Schleelein: Yeah. And the argument it came down to was: Is context important? Can a white person say that word without any repercussion? What is the exact context, if that is okay?

Johnson: Me personally, I say no.

Schleelein: Of course. It'd have to be really funny, right? Maybe not. But this is the thing we were talking about: context. If you can't understand the idea that at some point it's funny and that at some points it's not, and you don't appreciably recognize the difference, then fuck you. You're out.

Question: What kind of context would make it funny, in your opinion?

Arashiba: God knows.

Schleelein: I don't know. Dave Chapelle could probably do a good one.

Johnson: Context for a white guy saying it.

Schleelein: Oh no, for white man - that'll be such a fine line.

Johnson: Repeating a black guy saying it. Right there, as the black guy said it.

Schleelein: Yeah. There'd have to be a level of protection. If you're at all a decent person to make that joke. (personal conversation)

This debate also relates to the question of what white people are qualified to talk about, especially if it involves scenes representing enslavement:

Arashiba: It's higher mathematics. You know that in some ideal world, a white guy can make a slavery joke. 


\section{Johnson: Sure!}

Arashiba: What's the math? What's the setup? How do you get to that so that it's funny and it's true, and it's not a stupid caricature?

Johnson: As long as the person doing their bit is being genuine about what their story is. Like Derek, this white guy here, he's doing a really great white Muslim. His white Muslim character is literally grounded in the reality of what black progression is. And that matters. It matters if you're grounded in the reality of what your situation is. Say you're a pony. If you're playing a pony on stage, but you care about pony shit, you care about your pony, you can talk about that pony's feelings eating gummy bears. I hope that is not too weird. You have to care about what you're playing. At least myself, when I am doing my little improv shit - as long as I am invested in whatever it is, it'll work, and it'll be funny. (personal conversation)

I believe the term's performative and affective function is lost in this debate on the moral (il)legitimacy of white people using the n-word. Those referred to and affected by the use and denotation of the n-word are not - discursively - part of that political sphere, so their position cannot be made entirely intelligible for those living as the white referent-we for which anti-Black abjection is constitutive, as in the use of the n-word. Letting go of the capacity to apply, imagine, and perform this term, so instrumental in the generation of white modern subjectivity, would involve the disintegration of our current subjectivity and thus challenge Western sociability at large. When sociopolitical subjectivity and psychic-as-physical integrity is at stake, the culturally specific bios/mythoi praxis of contemporary Western being Human as Man must industriously seek lines of defense for using this term. By using the n-word - and all other anti-Black procedures - we white people undergo an abjective experience with the least possible effort. And more often than not, we are not even aware of it. We can therefore think of anti-Black abjection as action, perception, and imagination. I suggest that even the act of imagining the $\mathrm{n}$-word functions as anti-Black abjection; while no outward act violates Black-racialized bodies, it still activates the substantial (and perhaps more efficient) dynamic of the modern sociogenic principle as it pertains to modern Man's biopsyche. This I believe to be true for all elements or modes, artifacts, or gestures racialized and marked as Black by the white subject-body. The way in which the white subject draws upon, fears, partakes in, or desires Blackness for its own self-making, aiming at the subject-effect qua abjection, can occur through conscious acts or involuntary abjective sensations. 


\section{Affective transumption}

A telling and relevant incident took place at an improv workshop I attended in Bremen in 2014, when two white German improvisers used the term digger / digga / diggah in a scene. The term can be spelled in different ways and entered the German language via the Hamburg hip-hop scene in the 1990s. While I never write out the n-word, I do write out this transumption of it. Nobody would understand what the "d-word" means, which is precisely the point I make in this section. In (semi-)journalistic considerations of the term digger or its variants, it is commonly argued that it derives from the German Dicker (meaning "thick one"), a functional appellation for people with whom one has a close, trusting, thick friendship. Phonetically, this is plausible, as the Hamburg accent softens hard consonants in the middle of a word. Some attempts to historicize the usage of the term invoke the so-called Barmbek Basch dialect in specific working-class milieus in Hamburg in the early twentieth century. Today, the term is a "perennial favorite in teenage slang" (Assmann, my translation), and it is regularly suggested that "unlike many other rap terms it has not been imported from the USA" because the English term digger has a different meaning (Kurby, my translation). These arguments, however, miss the point. Even if the term is of German origin and cannot be traced back to the English word etymologically, the logic, validity, and significance of this position must be called into question. The d-word has gained momentum since its early German hip-hop usage, and because the predominantly white connoisseurs of predominantly white early Hamburg hip-hop culture have now grown up, it is now widely used throughout Germany in all sorts of milieus, sometimes more and sometimes less ironically. (Irony is, of course, insignificant with regard to the libidinal effect of a term's usage, but is often used to justify the specific way of attaining the very same biochemical effect, not unlike the fist bump so commonly used these days with varying degrees of irony but with great performative stability.) In the workshop, two male players improvised a German-language scene using that word repeatedly, presumably poking fun at what they presented as a deranged hip-hop youth culture with a playful regional feud between Bremen and Hamburg also feeding into it. When the scene was done, two white Americans in the workshop asked what that was about and were met with silence. They were confused by what was, for them, a shamelessly racist performance of stereotypically Black demeanor and the repeated use of what they understood to be the n-word. The Germans in the room were quick to explain the etymological and regional arguments to defend the term's use, and it was left at that.

The arguments they put forward may or may be etymologically correct. Yet given the contemporary use and function of the term, they are of no relevance. 
The conceptual and functional overlaps between the $\mathrm{d}$ - and the n-word are too obvious, as are the hip-hop context and its specific aesthetics of expression, the performative gestures and adopted attitudes that accompany it. The two common ways of spelling it are too similar (with -er or - $a$ at the end), and the term is too immediately a specific expressive gesture within an already anti-Black cultural context of Black imitation/obliteration. The d-word cannot reasonably be delinked from the n-word. (To do it all the same requires active white abjective ignorance, which is what we observe here.) Importantly, as this example shows, the term is used predominantly among white people in contexts and situations in which they imitate what they subliminally understand as Blackness. It is an anti-Black abjective term that thrives in an anti-Black abjective cultural and in the highly specific framework of white German hip-hop culture. Like Blackness, it is open and fungible, available for anyone. At the same time, it can function as a means to aggrandize Hamburg hip-hop culture (and its representatives), supporting claims for that city as the originary and the most authentic local hip-hop culture in Germany, the presumed original gangstas so to speak, against its widespread use. In one of its more recent and widespread articulations, the song “Ahnma” by Beginner makes this claim: "Everyone says 'Dicker' nowadays / We're putting Hamburg back on the map" ("Jeder sagt Dicker heutzutage / Wir packen Hamburg wieder auf die Karte.”) Though this example might appear to be locally specific and structurally insignificant, it points to something larger: the transumption of an affect trigger to the point of timeless unrecognizability. That is, the transumptive process doesn't change the affective function, but adds more and more layers to the veil that hides its anti-Black origin. Only a small selection of the speakers who use the term would consciously think of the n-word, which many would even consciously avoid for its racism. However, the effect that the d-word has on a white subject's body is similar if not the same: a close relative or a derivative of it, perhaps slightly less intense. Etymological arguments can never account for the power and popularity of the term today. Reading it within anti-Black abjection can. What we can take from this brief consideration is the idea that abjective transumption can account for anti-Black abjection without Blackness being visibly mobilized. A discursive entity with abjective powers for whites appears to be entirely stripped of its originary Blackness. This is a transumption of anti-Black affect into non-recognizability of the n-word as its ur-trigger. ${ }^{11}$

11 To be clear: I am not making any statement about the legitimacy of using the term, or whether this legitimacy could or should be raced in the sense that white people or Black people respectively should or should not use it. This is merely a consideration of the structures in which this term exists, and which ensure its discursive fortitude. On the same note, in two in- 


\subsection{Embodying anti-Black abjection}

\section{Sociogenic grounds}

Neuroscience is on the march and has begun to do important work, proving the existence of what is regularly called "implicit racial bias." Studies consistently show that unconscious racial bias has real-world effects, for example in police shootings (Hehman et al.), employment (Pager et al.), healthcare (Hoffman et al.), or infant health (Orchard and Price). Such studies are significant for raising awareness. However, they all implicitly draw on the white default position, because unconscious racial bias is only implicit for those whose white universalized bodies perform it. Those affected by it negatively do not need such scientific proof. Consequently, these studies, on the whole, are slowly exhausting themselves in the discovery of more and more fields in which unconscious racial bias can be observed. Further, the rhetorics of generalized bias, of which the racial variant is one among others, quickly fall into the rhetorics of relational discrimination, which do not communicate with an Afro-pessimist theoretical framework. However, in her theorizations of the sociogenic principle, Sylvia Wynter regularly draws on the findings and perspectives of cognitive science and substantializes her theorization through neuroscientific empiricism. There are good reasons for this: the whole field I address as embodied cognition seems to stand right where Wynter explores the ways and workings of sociogeny. Embodied cognition can indeed be mobilized to analyze what happens in the interplay between bios and mythoi, helping us to concretize the ways in which language, words, and stories shape and inform our biological existence, which in turn prefigures how we can think and feel about the world we live in. In this section, I briefly introduce a few central ideas behind embodied cognition and the trope of the body-brain to denote a body that corresponds to Wynter's idea of being human in bios/mythoi hybridity. With recourse to the influential neuroscientist Antonio Damasio, I zoom in on the concept of somatic markers. Referencing the discussion above, I hypothesize that we can conceive of anti-Black

stances in this project I had used the racial terms "dreadlocks" and "dreading hair." Even though I was fully aware of the meaning of the verb "to dread" and the adjective "dreadful," in this particular context I always understood it simply to mean "twisted hair." There is no German equivalent of the term, so for me it seemed a neutral loan word for a hairstyle racialized as Black. In other words, my white epistemological position enabled me simultaneously to know and not to know the connotations of the term - and empowered me to ignore the fact that there are no neutral terms in a racialized domain. I am grateful to my editor Annie Moore for pointing this out to me. 
abjection as the continual praxis of generating psychobiological homeostasis, that is, the somatic state of a subject-effect or a biochemical "sense of self," to use Wynter's phrase ("Principle" 54).

As the nomenclature suggests, embodied cognition helps us think of the rational and the biological functioning as a "single unit," against their differentiation in Cartesian tradition (Claxton 78). Theorists of embodied cognition - behavioral neuroscientists, neurologists, biopsychologists - provide evidence for the fact that "the body is self-governing" with no "big boss in the brain who forces through resolutions and dictates policy" (80). The brain does coordinate a lot of information: electrical impulses travel along a looping trajectory via the "autonomic and central nervous systems to and from the brain [...] chemical messengers that flow through blood stream and lymph system," including physical information about body movement and the wider as well as the microscopic scale (81-82). The entirety of this "maelstrom of physico-electro-chemical activity" comes together in the brain (87), where the various systems and their "ambassadors" confer (89). Yet the brain is one bodily function or system among others. While consciousness may be said to reside in the brain, this organ is no less physical, biological, or chemical than the rest of the body. In reference to the transumed dichotomy of High Reason/Irrationality, then, we must assert that the higher faculty is not so high after all. Further, and in keeping with a long tradition in affect theory, for theorizers of embodied cognition the body is not fixed and stable but in constant motion. ${ }^{12}$ Claxton states that "we exist by happening" (36), and that "the human body is a verb" (54). For him, this means that our information processing procedures are constantly present and continually updating, even though certain information can be foregrounded over other information within the brain. He applies the metaphor of a wave:

On the gross level, the wave keeps its form, but the water - the content - keeps changing. At any "moment," the wave represents the sum of total of all currents, swells and winds that are acting at that location. They come together to create a particular wave-form, with its signature composition and direction. Waves have a width; that is, they integrate the forces acting not at a point but over a small region of the ocean. The biological constraints of this span of integration might well account for the tenth-of-a-second duration of these apparent "moments." But each momentary wave is not separated from the moment before and the moment after. Like a real wave, it has both a leading and a trailing edge. It is simultaneously rising, existing and fading. In the rising are expectations and predictions of

12 At least since Spinoza, the forefather of affect theory, the idea that living bodies are not fixed and stable but in motion has been developed in many theoretical avenues. For Wynter, too, the destabilization of Humanism by de-conceiving it as a praxis of being human is central. This position also provides the axiomatic ground for the theorization of abjection as praxis. 
what the future may bring, and in the fading are the echoes of the confirmations and surprises that arose from those moments that have just been. [...] (We might, if we're feeling whimsical, see the properties of the seawater itself as the capabilities of the body to behave; the current and groundswells as the values and concerns in play at that location in time and space; and the winds as the influences from the external world). (91)

The body-brain decides from moment to moment "what is the next best thing to do" (10). How and why human beings decide what to do in a given situation, what drives their behavior and structures their way of being and behaving in the world, is central to the study of embodied cognition. Together with the awareness of the body-brain functioning as a single unit, we are engaging with how "the 'decision-making' of the brain can be influenced by a badly behaved bacterium in the gut, and the level of sugar in the blood can be altered by a squeak or a dream" (4-5). Without going into much more detail, let me emphasize with Claxton that "the brain is not just in the business of telling the body what to do. [...] Body and brain are tied together so intricately and so rapidly that it makes no sense to locate all the 'intelligence' in one and none in the other" (87). It must be understood that "intelligence can be embodied in physical structures, and that some structures can therefore take some of the strains of minds and brains" (41). This, in effect, breaks down the modern dichotomy (and its theocentric and ancient predecessors) that prefigures the white subject on the grounds of Reason as opposed to the sphere of Blackness and irrationality. Moreover, "much of our somatic intelligence operates unconsciously, without conscious supervision or even awareness" (Claxton 7). Though perhaps not entirely zombies, robots, or computers, we are certainly far more limited than many are willing to accept or even realize. ${ }^{13}$

Importantly, embodied cognition can tell us a lot about the function and functioning of emotions. No longer are they understood as separate from rationality. Emotions "involve muscles and glands, blood, sweat and tears, as well as thoughts, memories and imaginings" (Claxton 103). They are the "most obvious place where we experience our bodies, brains and minds coming together." Rather than separating emotions from rationality, "[w]e must begin by seeing emotions as contributing to our ability to act intelligently, not as impediments to such action" (103). Claxton considers emotions "deep, bodily-based constituents of every kind of human intelligence" (104). For proponents of embodied cognition theory, emotions are "built-in 'default' settings of our whole embodied systems” (104), automatically activated as responses to significant events:

13 Note, though, that the recognition of these limitations decidedly does not imply their transcendence. The author of these lines also has a body. 
If we see something as an object of desire we are automatically primed to approach and secure it. If we are hungry we start looking around for sources of food. [...] if we see an aspect of our world as dangerous, we prepare to avoid or neutralise it. [...] Though they come in many shades, emotions are intelligent responses to events that are relevant to what we value - and what we value has its roots firmly in the physical body. (105)

An emotional state is a response to a cue that signifies such important events. They are not "not actions in themselves, but anticipatory states of readiness to respond to events that, we suspect, might be about to unfold." These states of readiness are pre-settings of affective configurations, not unlike those "that come with the audio amplifier on a modern TV" (106). They combine biological, chemical, and physical phenomena that manifest in and through the body. ${ }^{14}$ Yet the recognition of these aspects, and presumably many others not mentioned here, should not leave the impression that they are hierarchically structured or that there is a certain protocol in their sequencing. Embodied cognition theory recognizes that - even though different parts fulfill different functions - the whole body is part of this configuration, and it is unhelpful to seek to disentangle what the brain or other parts of the body do on their own:

These whole "body+brain+sensors" reactions are so intricately interwoven that it is impossible for us to pull them apart and tell what is "cause" and what is "effect." The circular loops connecting body and brain are bi-directional, so that "higher" processes are influencing "lower" ones, at the same time as the "lower" are feeding information up to the "higher." Words like "resonance" and "reverberation" capture this shimmering complexity much

14 To get a clearer idea of what this means, I quote the paragraph from Claxton in full: Which bits of our bodies do emotions engage? The broad answer is: almost all of them. But it may help to highlight some of the most important. First, our internal physiology can be altered. [T] his can include changes to heart rate and blood pressure, rate and depth of breathing, the physical and chemical behavior of the intestines, and the chemical composition of the blood and lymph. In addition, aspects of bodily posture, facial expression and voice quality can change. Our shoulders may drop, or faces become angular and forbidding or tender and loving, and our voices grow hard or soft, loud or quiet. The skin changes color as its blood supply increases or decreases - our cheeks burn with embarrassment or become pale with rage - as well as changing in sensitivity and sweetness, and our body hair can stand on end. The big action muscles of arms, legs, shoulders, neck and so on can be tensed or relaxed, and fingers get ready to ball into fists or stretch out into soft instruments of caress. Actions may become slow and ponderous, or sprightly and vivacious. Sensory muscles are affected: eyes move in their sockets, pupils dilate or contract, nostrils twitch [...] Eye contact is penetrating or steely, or the gaze averted or shy. And the brain sets up patterns of expectation and prediction: some constellations of attention, memory, thought and imagination become primed; others may fade into the background. (107) 
better than ides of "stimulus" and "response." Did I see the bear, feel afraid, and so tell my legs to run? Or did the unfolding of bear-seeing, gut-trembling and leg-thrusting happen in such a fast and loopy fashion that they are, in fact, different facets of the same holistic episode? Traditional "folk psychology" tells us the former. Embodied science tells us the latter. (106)

The body experiences various emotional modes that involve the body-brain Claxton lists distress, recovery, disgust, fear, anger, sorrow, shame, desire, inquiry, care, and anxiety, though others suggest other groupings - and these are variable in themselves. (In the pre-set of Disco, you can still add bass.) As a consequence, there are infinite combinations and configurations for refining, nuancing, and modifying an emotion. Conceptualized as biophysical modes, then, emotions "can operate perfectly well at the physiological and behavioral levels without any need for conscious supervision, or even awareness" (118). Regardless of how individually refined or sophisticated emotions are experienced, and whether or not they reach consciousness, "they retain their rootedness in the physical workings of the body" (121). Human decision-making - figuring out the next best thing to do - must be viewed in light of this physiological reality. Not only is so-called "rational thinking" fundamentally physical (that is, chemical and biological), but the body very often knows more and faster than logical processing could function on its own - if it could function without it at all. Indeed, the body often knows better and learns faster without the mind, even in matters traditionally related to the mind. Even though decisions are ultimately made in the brain, they are not rational. The brain itself is more like a conductor of a heterogenous choir and decides which songs to sing at the concert: "Each of the possible courses of action under consideration gets tagged with a number of indicators that will help the brain to do its job of conducting the somatic orchestra" (Claxton 98).

\section{Somatic marking of Blackness}

In Descartes' Error, Antonio Damasio conceptualizes and empirically substantializes emotions as visceral - a tremendous contribution to the study of embodied cognition. What Damasio contributes to this project is his differentiation between what is natural, what is learned, and what is cultured. He also distinguishes between primary (innate, "early") and secondary (learned, "adult") emotions. Primary emotions are "pre-organized mechanisms" (a term borrowed from William James) wired into our bodies before we learn anything. Without the interference of consciousness, our bodies react to stimuli from within or outside themselves. 
These are not necessarily concrete objects but rather features such as size (large animals), a particular type of motion (for instance, reptilian), or sounds (like growling). Such stimuli - or combinations thereof - can be "processed and then detected by a component of the brain's limbic system, say, the amygdala; its neuron nuclei possess a dispositional representation [of those stimuli] which triggers the enactment of a body state characteristic of the emotion of fear" (131). The whole procedure may remain outside consciousness to the degree that one does not need much knowledge about the object, or even to recognize it; "all that is required is that early sensory cortices detect and categorize the key feature or features of a given entity" (131). An emotion is thus best understood as "a change in your body state defined by several modifications in different body regions" (135). Damasio's explication clarifies how this conceptual framework resonates very strongly with the libidinal economy and its homeostatic ideal:

As a whole, the set of alterations in the body defines a profile of departures from a range of average states corresponding to functional balance, or homeostasis, within which the organism's economy operates probably at best, with lesser energy expenditure and simpler and faster adjustments. (135)

With Damasio, I understand an emotion "as the collection of changes in the body state that are induced in myriad organs by nerve cell terminals, under the control of a dedicated brain system, which is responding to the content of thoughts relative to a particular event or entity" (139). Some of these changes are perceptible by an outside observer (such as body posture, ways of moving, or sweat intensity), while others are "perceptible only to the owner of the body in which they take place" (139). All of these serve the homeostatic ideal, material, psychic, libidinal. How do we get from primary, early childhood emotions to secondary, adult emotions?

For a secondary emotion to be realized, we need to be able to feel it. The emotion, a specific change in the configuration of the continual affective wave, must reach consciousness. Once we become conscious of what happens in the body, we can subtract further information from the emotional event in relation to what triggered it, which helps us to apply that knowledge in the future to make different decisions. Damasio writes:

Feeling your emotional states, which is to say being conscious of emotions, offers you flexibility of response based on the particular history of your interactions with the environment. Although you need innate devices to start the ball of knowledge rolling, feelings offer you something extra. (133) 
Where primary emotions serve as the basic structure of human emotional life and our personal and social behavior, they "are followed by secondary emotions, which occur once we begin experiencing feelings and forming systemic connections between categories of objects and situations, on the one hand, and primary emotions, on the other" (134). Whereas the limbic system and the amygdala suffice for the primary emotions to function effectively, other parts of the brain capable of representation are applied for secondary emotions: "the network must be broadened, and it requires the agency of the prefrontal and of somatosensory cortices" (134). What comprises an emotional experience of the second type? First comes a "conscious deliberate consideration you entertain about a person or a situation" (136). These are representations of images, some verbal, others non-verbal. Then, non-consciously, "networks in the prefrontal cortex automatically and involuntarily respond to signals arising from the processing of the above images" (136). Because these are reactions to a representation, they are necessarily acquired rather than innate, "although [...] the acquired dispositions are obtained under the influence of dispositions that are innate" (136). Then, "non-consciously, automatically and involuntarily, the response of [these] prefrontal dispositional representations is signaled to the amygdala and the anterior cingulate" (137), which causes the body to react: "viscera are placed in the state most commonly associated with the type of triggering situation," and the motor system and skeletal muscles express that emotion by completing the "external picture" (138). Chemicals are released that result in changes in the body-brain. An actual situation can trigger them by way of memory or imagination. The representational faculties within the brain are the same ones that trigger the biochemical reactions making up the emotion.

The emotion as such, the tidal wave that floods the body, is a different phenomenon from its conscious perception and interpretation, let alone from the linkage between the emotional wave and the signal that caused it in the first place. For this process as well as its outcome, Damasio reserves the term "feelings.” For a body-brain to register an emotion consciously, it must be represented in the brain and signaled "through nerve terminals that bring to it impulses from skin, blood vessels, viscera, voluntary muscles, joints, and so on” (143). The somatosensory cortices in the insular and parietal regions "receive an account of what is happening in your body, from moment to moment," and thus "get a 'view' of the ever-changing landscape of your body during an emotion" (144). Parallel to this neural information, information also comes through a different channel, a "chemical trip": "Hormones and peptides released in the body during the emotion can reach the brain via the bloodstream, and penetrate the brain actively" (144). This means that the brain gets information not only about what is happening in the body, but is also instructed about the way it should 
work with or respond to that information: "What gives the body landscape its character at a given moment is not just a set of neural signals but also a set of chemical signals that modify the mode in which neural signals are processed" (145). If the essence of emotion is the basic experience of the body, the essence of feeling is the "process of continuous monitoring, that experience of what your body is doing while thoughts about specific contents roll by" (145). Feelings are thus what happens when emotions are consciously attached to the signals that cause them: "a feeling depends on the juxtaposition of an image of the body proper [i.e., the current body state] to an image of something else, such as the visual image of a face or the auditory image of a melody" (145). A feeling, then, is always about something; it links an emotion to an external stimulus and lets us reflect on that link.

Notably, the image of the signal and the subsequent (!) image of an emotion must be kept separate. They do not become one. And like a sign and its referent, they are arbitrary. The combinations may be "unexpected and sometimes unwelcome. Their psychological motivation may be unapparent or non-existent, the process arising in a psychological neutral physiological change” (146). The separateness of the two representations not only "affirm[s] the relative autonomy of the neural machinery behind the emotions" but also "reminds us of the existence of a vast domain of nonconscious processes, some part of which is amenable to psychological explanation and some part which is not." This is why white people cannot but actively abject Blackness when we encounter it. When Hillary Clinton stated during her 2016 presidential campaign that "Black men can be scary," she addressed and universalized a culturally specific white feeling, acknowledging an emotion that (structurally) only white subjects know without recognizing it as a white solipsist event rather than a feature of Blackness, something that Black-racialized bodies are assumed to be. Understanding the difference between emotions and feelings might have instructed her to do otherwise. But even if I can ponder why I feel a certain way about a certain thing, this does not mean I can control the emotion that underlies the feeling. I can judge it, be ashamed or proud of it, but I cannot change it voluntarily, even with the best of intentions. In the world as we know it, we will always remain voluntary or involuntary anti-Black abjectors.

\section{Racializing the subject-aeffect}

Bringing psychoanalysis in conversation with embodied cognition, I posit Kristeva's notion of subject-effect as an emotion understood in the language of embodied cognition. In order to mark this biochemically affective dimension in its cul- 
turally specific relation to abjection, I modify Kristeva's term "subject-effect" slightly into a "subject-aeffect." The ligature is a helpful reminder that we are concerned with a subsequent consequence of a culturally determined action or perception as well as its embodiment. Understood as a secondary emotion in Damasio's sense, the subject-aeffect is grounded in a "conscious deliberate consideration you entertain about a person or a situation," such as the perception of a signifier (verbal, sonic, linguistic, physical, imaginary, or real) marked as Black, followed by the non-conscious activities of "networks in the prefrontal cortex [that] automatically and involuntarily respond to signals arising from the processing of the above images" (136). I locate the subject-aeffect in the very space where a secondary emotion draws on the nonconscious workings of the body-brain to discursively naturalize an affective wave, even though the linkage between the trigger and the effect is arbitrary. Damasio writes:

Nature, with its tinkerish knack for economy, did not select independent mechanisms for expressing primary and secondary emotions. It simply allowed secondary emotions to be expressed by the same channel already prepared to convey primary emotions. (139)

Crucially, I believe that this accounts for genuine misinterpretations about the world and ill-fated debates about whether "Black Men can be scary." What feels right in the body is not necessarily natural and correct, just because the body is an object of nature. With Wynter, we must understand our subjectivities as well as our body-brains as bios/mythoi hybrids. The necessarily abjective (imagined or real) encounter of a white subject with a thing, body, mode, image, or other phenomenon signifying Blackness is both conscious (it must be read as Black) and unconscious because, as whites, we may not deeply understand the emotions it gives us, but remain on the level of feelings, registering a bodily sensation linked to a given perception. We may consciously describe a fear of Black men, observe an emotional-sexual inclination toward racialized porn, or interpret ourselves intellectually as connoisseurs of jazz; we may fear Black-racialized neighborhoods, feel revolutionary copying hairstyles, or imagine our own transcendence when we improvise. In the register of feelings, white subjects can discuss innumerable nuances of the subject-aeffect as a somatic state, but it remains grounded in subject-aeffective emotions structured by anti-Blackness. The visceral experience, the affective wave I name "subject-aeffect," the exclusively white experience of one's own physical and symbolic integrity, the "sense of self" (Wynter, "Principle" 54) is not an action in itself - it is caused by anti-Black abjection, which, as a structurally prescribed (inward or outward) performance, happens on the level of sociogeny. We can understand it as a pedagogical procedure that a) teaches the white subject of modernity "how to be a 
good man or woman of its kind," (Davis qtd. in Wynter, "Unsettling” 271), that is, how to have a subject-aeffect, the visceral experience of a sense of self, and b), permanently ingrains this knowledge in the white subject's body-brain.

Language is essential to this procedure. Through language, the infant enters the symbolic system and gains access to its affective, emotional repertoire. When Aasia Bullock observes (about the use of the n-word on the improv stage) that "words mean things" (personal conversation), her claim resonates with Claxton's assertion that "[w]ords are ways of activating neural circuitry (and altering biochemical processes) through speech and writing” (147). Any affective occurrence in the body shapes and trains the emotional registry. While there is something to be said for life-long learning, the affective repertoire in which we have been trained (and the semantically arrested cathexis that structures our individual and collective libidinal economy as it develops throughout infancy, childhood, and adolescence) powerfully hardwires all our decision-making and emotional structures. It defines what homeostasis means for white subjects within the white modern culturally specific genre of being human as Man. From the moment we can isolate a word or phrase and attribute an experience (observed, undergone, or both), from our earliest engagement with or perception of the n-word (or any other signifier affectively read as Blackness), our neural circuitry programs us to be the anti-Black abjector-subjects that the matrix of modernity prefigures and demands. It hardwires us biochemically to attain homeostasis easily via anti-Black abjection. I think this is part of what Sylvia Wynter addresses in theorizing the sociogenic principle and how logos and mythoi concretely inform our being as bios.

\section{Somatic solipsisms of the languaging white body}

Damasio's somatic marker hypothesis posits that part of our decision-making is motivated by conscious or unconscious knowledge (and thus ignorance) of the possible outcomes of various reactions to objects, situations, events, people, or circumstances. Arguing with Pascal that "[w]e almost never think of the present, and when we do, it is only to see what light it throws on our plans for the future" (qtd. 165), Damasio explains that in any given situation that demands action, our mind is "replete with a diverse repertoire of images" about what could happen if we did this or another thing (170). This corresponds to the moment-tomoment decision-making Claxton describes as the continual assessment of "the next best thing to do" (10). Damasio thinks of it as the "selection of a response option" and similarly departs from the Cartesian or Platonic "high-reason view" of decision-making, that is, the idea that Human beings as rational subjects can 
arrive at ideal assessments of situations purely by intellectual labor detached from sentiment (165). He emphasizes that decision-making is largely based on unconscious and somatic preselection. His argument primarily runs along the lines of reducing response options on the grounds of negative experiences. If a certain response option to a given stimulus has been experienced as sufficiently negative, that option will automatically be dysselected before we have the chance to think about it: "When the bad outcome connected with a given response option comes into mind, however fleetingly, we experience an unpleasant gut feeling" (173). Similarly, when a good outcome is connected with a certain response option, this will also be sedimented in the body-brain and manifest within an internal preference system:

somatic markers are a special instance of feelings generated from secondary emotions. Those emotions and feelings have been connected, by learning to, to predicated future outcomes of certain scenarios. When a negative somatic marker is juxtaposed to a particular future outcome, the combination functions as an alarm bell. When a positive somatic marker is juxtaposed instead, it becomes a beacon of incentive. (174)

Based on somatic markers, the body-brain makes decisions without our being conscious of it. Damasio uses the term "body loop" to describe the complex set of biochemical interactions or the somatically marked pre-sets of the affective wave, the specific neural circuitry that constitutes a certain "marker."

The fact that the machinery of primary emotions generates biochemical and mechanic bodily responses to a stimulus does not affect the assertion that "most somatic markers we use for rational decision-making probably were created in our brains during the process of education and socialization, by connecting specific classes of stimuli with specific classes of somatic state" (177). In other words, they are based on secondary emotions:

Early in development, punishment and reward are delivered not only by the entities themselves [which later call for a response] but by parents and other elders and peers, who usually embody the social conventions and ethics of the culture to which the organism belongs. (179)

Somatic markers are not trained in one-to-one real-life situations but in the observation of interactions with those identifiable individuals who model behavior and regulate the child's actions through sanctions or rewards. Without having theoretical backing here, I think it is safe to say that at a certain phase of development, there is nothing more imperative than to "be a good one of one's kind" (Davis qtd. in Wynter, "Unsettling” 271). The child seeks to achieve this recognition by way of imitation (words, actions, mimics, gestures) even if it does not un- 
derstand them in their grown-up meanings. Words, gestures, and so on thus attain an affective meaning without the linguistic differentiation an adult may (or may not) draw on. I believe this is what Claxton refers to in his example of a child attaching the somatic marker of disgust: "If Mummy makes a face of disgust when I start to investigate the food in the dog's bowl, I learn to attach my own disgust to similar sights and smells" (122). Even though this is a life-long process, the "critical, formative set of stimuli to somatic parings is, no doubt, acquired in childhood and adolescence” (Damasio 179), when we develop the words our mouth prefers to utter (Lyotard 2). This is when we learn our culturally specific subjectivity, enact it, find it, and maintain it. This is when the amygdala and the limbic system are formed most intensely. In this phase we learn deeply and our "internal preference system and sets of external circumstances extend the repertory of stimuli that will become automatically marked" (Damasio 179). It is also when our body begins to language by interpreting, applying, and making sense - hence the central role of children's books in Fanon's theorization. Every reaction we observe in our parents or peers towards any object, mode, or phenomenon racialized as Black will structure and predetermine our emotional reactions to Blackness as a white subject. Here I mean Blackness in all its forms: individuals, sounds, spaces, modes, and aesthetics. Just as we learn from "Mummy's face of disgust" (Claxton 122) not to touch the dog's bowl, we white people learn from daddy's joyful or sorrowful grimace when he practices the blues on his guitar most authentically, from our aunt's anxiously tightening her grip when a group of young Black men walk past, from the favorite cousin's relaxed face when he smokes weed and listens to Bob Marley or their anger when putting on Public Enemy. By observation, we develop an internal preference system that serves us to perform body states and behaviors we like, most explicitly in the praxis of anti-Black abjection as it leads to the "functioning balanced biological states" (Damasio 179), providing us white subjects with a subject-aeffect. Again, this highlights a culturally specific, distinct emotional pre-set, a more or less defined affective configuration of the body-brain's various dimension of anti-Black abjection as the visceral performance towards the anticipated somatic state of the subject-aeffect, which our consciousness may register merely as unraced homeostasis. ${ }^{15}$

15 Damasio writes that "the buildup of adaptive somatic markers requires that both brain and culture be normal” (177). This means that a somatic marker that aids social adaptability will necessarily be anti-Black. The somatic marker hypothesis thus helps to conceptualize how white culture ingrains whiteness in its subjects, how it naturalizes white abjectorship by inscribing it on all levels and regions of the body. Even though arbitrary and violent in its myriad manifestations, anti-Blackness is normal, ensuring the white supremacist culture of the modern West 
Considering the subject-aeffect instigated by abjection as an emotion in Damasio's terms, as a psychobiological body loop, that can (potentially) be defined in terms of biochemical reactions and set apart from other body loops whatever the precise emotional profile may look like - we can say that the moment of subject-making will register in and for the body-brain as a very distinct emotion - or a clearly definable combination thereof. Damasio identifies the five fundamental emotions as happiness, sadness, anger, fear, and disgust, each with variations like "euphoria and ecstasy" for happiness (149). We can assume that combinations of happiness and fear must also be possible - otherwise, "horror" as a combination of happiness and fear would not succeed. Without being in the position to detail the chemical, biophysical, or neurological specificities of a relatively complex body loop, we can still think about the specifically anti-Black, abjective subject-aeffect as an emotion in Damasio's sense. We might even go as far as to speculate that it has two (or more) levels. This way we can make sense of the fact that what we may experience as separate feelings (fear and desire) are superficially disparate, but draw on the same underlying sensation of experiencing a sense of self. Fear and desire, then, are two ends of the subject-making continuum in the white libidinal economy.

While cultural studies has long adopted psychoanalytic approaches, to my knowledge few neuroscientists have been interested in or conceptualized such a link. This appears to me grave neglect as it would help us to further materialize the kind of culturally specific abjective subject-making phobia (negrophobia) and the culturally specific abjective subject-making desire (negrophilia) I have elaborated here. Turning to Kristeva opens up this line of thought as well:

\begin{abstract}
Let me say that want and aggressivity are chronologically separable but logically coextensive. Aggressivity [...] merely takes revenge on initial frustrations. But what can be known about their connection is that want and aggressivity are adapted to one another. [...] Fear and the aggressivity intended to protect me from some not yet localizable course are projected and come back to me from the outside: "I am threatened." The fantasy of incorporation by means of which I attempt to escape fear (I incorporate a portion of my mother's body, her breast, and thus hold on to her) threatens me nonetheless, for a symbolic, paternal prohibition already dwells in me on account of my learning to speak at the same time. In the face of this second threat, a completely symbolic one, I attempt another procedure: I am not the one that devours, I am being devoured by him. (39)
\end{abstract}

It is worth pointing out that the "fantasy of incorporation" as a way of dealing with abject, phobic Blackness resonates with bell hooks's famous essay "Eating

remains healthy. (Despite the fact that we might describe that very culture as sick or pathological.) 
the Other." Whether the individual in question needs a libidinal boost to conceive of themselves as fully Human (personally or socially), Blackness provides the portal to that very white jouissance. Even though the causal link is arbitrary and logically wrong, as white people, we are always bound to feel phobia/want in our encounters with Blackness qua abjection. Reading Blackness as a somatic marker means that Blackness (or the sphere of Blackness and whatever is abjected into it) refers to a floating signifier, a multidimensional yet elusive sign with no actual referent. Blackness itself does not denote anything and has no core, cultural or otherwise. Blackness gets attached to semiotic materialities that are not necessarily connected to each other on ontological grounds. Blackness is constructed by white people and attached to actions, motions, styles of music, activities, sounds, geographies, levels of income, gestures, fields of profession, types of sport, and ways of speaking, all racialized as Black. A white subjectbody is the only locus where Blackness attains this abjective meaning in the form of the biophysical image or map that presents to consciousness the goings-on of the body in its encounter with Blackness. A brief and final look into Damasio's explication of the term somatic marker helps to illustrate this: "Because the feeling is about the body, I gave the phenomenon the technical term somatic state [...] and because it 'marks' an image, I called it a marker" (173). ${ }^{16}$ Although we are looking at the effect of a signal on the body the affect attached feeds back into the real world. Our biochemical reaction to the signbearer marks that sign-bearer. Our emotion marks the external world. Blackness exists as a praxis of abjection because white libidinal economy relies on the never-ending abjective marking of what it construes as Black.

I suggest the oxymoron "solipsist encounters" to describe and denote the fact that a white subject cannot encounter a Black person without being thrown into some sort of solipsistic communication with themselves. White subjects' reactions have nothing to do with the Black-racialized individual standing in front of them and everything to do with the abjection necessary for their own subjectivity. These abjective perceptions, voluntary or involuntary, make any encounter with what is construed as Black a solipsistic event, inspired or triggered by an external stimulus that is actively and abjectively marked as Black. Given that

16 Note that the receiving body marks the external stimulus, which makes it an abjective act. This often gets unjustifiably twisted. It is essential to understand that a feeling a white individual has, involuntary as it may be, affects the external object. This relates to Freud's statement in "Claims" that "the principle function of the mental mechanism is to relieve the individual from the tensions created in him by his needs. One part of this task can be achieved by extracting satisfaction from the external world; and for this purpose, it is essential to have control over the real world" (186). 
anti-Blackness is the ground on which we symbolically conceive of ourselves as subject-bodies and ushers us into the political sphere of the modern West, antiBlack abjection becomes the defining procedure of somatic marking if there ever was one. The theoretical consequences as they pertain to interpersonal encounters are unnerving. As white-bodied subjects, we cannot control all our affective reactions to what we read and mark as Black, including people who are structurally racialized as Black - whether they are close friends, passing strangers, or celebrities. The ultimate consequence of this theorizing is that any encounter with those who bear the Burden of Blackness (Fanon) involves an intuitive, abjective impulse that takes place within white subjects. And it will also, in one way or another, emanate from our white subject-bodies as well. These are the familial ties of whiteness. The continuum of anti-Black abjectorship encompasses Roy Bryant murdering and mutilating Emmet Till, white scholars engaging Black Studies theory, white gamers selecting Black avatars for their gangsta roleplay, singers in a white gospel choir, and innumerable other abjective agents (and myriad functional personas for individual white subjects) who constitute the collective subject-body of the modern West.

As discussed above, I read anti-Black abjection as an act of experience, as an inward psychic procedure with outward effects, and as an action that is internally motivated and feeds back into the psyche. This approach is not designed to relativize the physical violence directed against actual bodies compared to the white youth listening to hip hop. But it is designed to allow me to talk about the way that anti-Black abjection lies at the core of white subjectivity, and not only for those who explicitly fashion themselves as white supremacists. Damasio's by now classic and widely-accepted notion of the body loop as well as its vacuous version, the as-if body-loop, speak to that. Both loops mark an external stimulus somatically. Both serve to activate a previously developed biochemical "pre-set," to use Claxton's term. The difference is that the primal body loop denotes the idea of an actual, genetic predisposition of the human body - for example, being wary of falling from a height. In a situation where we are approaching a great height, our body might know and react to it before it has been relayed to our somatosensory cortices. This involves an actual change in the body before our learned brain can send the relevant information back into the body. In the as-if body loop, on the other hand, "the body is bypassed and re-activation signals are conveyed to the somatosensory structures which then adopt the appropriate pattern" (Bechara et al. 297; see also Damasio et al.). This means that in a given situation, the body does not give the information about the danger to the brain, but rather the learned body-brain knows what to do first. This is how, when we speak of somatic marking, we are in the sphere of what Damasio calls secondary emotions. 
There is some danger in this transdisciplinary conflation of terms. The primal quality for Damasio addresses actually instinctive reactions to external stimuli. Assuming that anti-Blackness is genetically built into whiteness on this level would involve the actual, epistemic, and ontological naturalization of the Blackracialized body as inhuman on the grounds of culturally specific reactions to it. The psychoanalytic toolkit can, however, only be applied within language, even if the unconscious is assumed to exceed it. But this in no way disqualifies the connection; the results of both “the 'body loop' or the 'as-if body loop' may become overt (conscious) or remain covert (non-conscious)” (Bechara et al. 297). When talking about culturally specific abjection, then, we are within the sphere of the as if-body loop, which, as abjectors, we would not be able to differentiate from an actual body loop - both feel and are exactly the same when we notice them (overt somatic marking), and even when we don't (covert somatic marking). This means that, when reading anti-Black abjection as a secondary emotion, we must understand it in hybrid terms as a somatic marking of something real or imaginary, but observable as a physical act or experience, such as the perception or utterance of words. In Words Can Change Your Brain (2012), Newberg and Waldman argue for the power of language to materially, biophysically alter our brain structure, which corresponds directly to Sylvia Wynter's conception of being human as bio-mythoi hybrid practice. They argue that a word like "no" causes "a substantial increase of activity in your amygdala and the release of dozens of stress-producing hormones and neurotransmitters," which immediately interrupts "the normal functioning of the brain" (24). The youngest of the languaging Human bodies are thus prone to a learning experience that will sediment deeply in their bodies as affective knowledge: the more "negative thoughts they have, the more likely they are to experience emotional turmoil" (Newberg and Waldman 25). The more often they hear the word "no," the more vulnerable they are to clinical depression for the rest of their life. Newberg and Waldman also observe that "fearful words [such as] "'poverty,' 'sickness,' 'loneliness,' and 'death' [...] stimulate many centers of the brain, but they have a different effect from negative words." Rather than leading to depression, "the fight-or-flight reaction triggered by the amygdala causes us to begin fantasize about negative outcomes, and the brain then begins to rehearse possible counterstrategies that may or may not occur in the future" (25-26). These "fearful words" are somatically marked.

If a simple "no" can have this effect, how can we frame the power of the signifier "Blackness"? First, mobilizing Damasio's as-if body-loop and anti-Black abjection as inward (also imaginary) and outward (concrete action), we must re- 
member that the brain "does not distinguish between fantasies and facts when it perceives a negative [or other] event" (Newberg and Waldman 24-25). ${ }^{17}$ Second, our active performance strengthens whatever affective sensation a word provides for us: "If you vocalize your negativity, even more stress chemicals will be released, not only in your brain, but in the listener's brain as well” (Newberg and Waldman 24). ${ }^{18}$ Third, we must remember the evolution or development of our semiotic capabilities: "Before we learn to think in words, we instinctively think in pictures. As the brain continues to develop, we gain the ability to think in increasingly abstract ways," namely from picture to drawing to symbol to word, as Newberg and Waldman suggest (49). All of this is highly consequential when related to anti-Black abjection. Imagination, memory, actual encounters, fictional representation, factual representation - the list goes on - are all able to provide anti-Black affective jouissance. Adjudicating whether one mode is more powerful or efficient than another would be mere subjective speculation. Further, we must follow Broeck's assertion that abjection is primarily an act. If we utter anti-Black language (or perform outward anti-Black abjection in another way onto the world), it enhances our white sense of self, providing us with a white subject-aeffect. Finally, the whole procedure does not even need a physical manifestation of Blackness. There are "some words our mouth prefers to utter" (Lyotard 2) even if we white people do not understand why. While Newberg and Waldman are primarily interested in word language, I think we must also read any semiotic unit involving gestural, behavioral, sonic, or other in the meanings of Blackness - and all their real-world manifestations.

\section{Hybrid mode: the non-location of abjection in bios-mythoi}

I want to pause here to consider the relevance of Kristeva's concept of abjection in relation to racism. What do we make of the fact that her notion of abjection is in itself an elaborate manifestation of the modern matrix, given that it too assumes that we naturally feel disgust for physicality, fleshliness, the corpse? Can and should we consider it a workable concept for a critique of anti-Black-

17 There are even studies showing that the brain does not distinguish between physical and mental pain (see, for example, Eisenberger or Kross).

18 At this point, Newberg and Waldman consider words associated with negativity. However, in other sections, and in keeping with the general thrust of their book (which is mostly a self-help guide for communication and self-improvement), they quote from studies that demonstrate the positive effects that "positive" words have on the brain, even developing training techniques out of this fact. 
ness when it can so easily be mobilized to naturalize in ontogenetic terms? If so, where exactly do we locate the abjective process in Wynter's conception of being human as bios-mythoi hybridity? Martina Tißberger's criticism of Kristeva's abjection as mobilized by Derek Hook is constructive:

\begin{abstract}
Hook wants to explain racism with recourse to Kristeva's ontogenetic construct, which is in itself already prefigured by that very racism. It all fits together so nicely because one is the model for the other. Hook fails to take a closer look at abjection as an ontogenetic moment. He describes the infant's abjective process as "existential," "ontological," "natural," "essential," and "instinctive" in the struggle for "individual coherence," "wholeness," "identity." We learn nothing about why coherence and wholeness are so important that they are "produced instinctively" and have ontological quality. It seems natural from the Western perspective in a culture that values individuality and autonomy while judging collectivity and interdependence negatively. However, beyond the Western, hegemonic point of view, "coherence," "wholeness," and "identity" do not apply to the foundations of culture and subject. (48-49, my translation) ${ }^{19}$
\end{abstract}

Hook's discussion and mobilization of abjection as it relates to racism, and his concept of " "pre-discursive' racism," are not my reference for reasons in part considered in Tißberger (compare Hook, "Racism as Abjection" and "Prediscursive Racism"). However, I am aware that much of her criticism may also be directed against this project, and has remained unaddressed to this point. In itself and perhaps regarding its immediate object of critique, her argument has great validity. However, Tißberger's criticism is based on several axioms I do not share. "Taking a closer look at abjection as an ontogenetic moment," for example, is only imperative for those who aspire to an ontogenetic truth about humanity at all, focusing on the actuality of abjection for those who experience it. This is the crux of Tißberger's otherwise significant argument. The moment we think about and apply abjection as a tool to talk about an observable reality rather than as a vehicle that takes us to an (ontogenetic) truth, we are doing something else.

19 “Hook will im Rekurs auf Kristeva's ontogenetisches Konstrukt den Rassismus erklären, der bereits Kristeva's Konstrukt präfiguriert. Das alles passt so schön zusammen, weil eines des anderen Vorbild ist. Hook versäumt, Abjektion als ontogenetisches Moment genauer zu betrachten. Er beschreibt den Prozess der Abjektion beim Kleinkind >existenziell<, >ontologisch <, >natürlich $<$, > essenziell $<$ und >instinktiv $<$ im Kampf um >individuelle Kohärenz<, > Ganzheit<, >Identität $>$. Wir erfahren nichts darüber, warum Kohärenz und Ganzheit so wichtig sind, dass sie >instinktiv< hervorgebracht werden und ontologische Qualität haben. Es scheint selbstverständlich aus der westlichen Perspektive und ihrer Kultur, die Individualität und Autonomie wertschätzt, während sie Kollektivität und Interdependenz negativ bewertet. Jenseits des westlichen, hegemonialen Standpunktes gelten $>$ Kohärenz $<$, $>$ Ganzheit $>$ und $>$ Identität $<$ jedoch keineswegs als Grundfesten von Kultur und Subjekt” (48-49). 
In consequence, the argumentational circularity Tißberger points to - suggesting that abjection explains racism so aptly because it is modeled on that same racism - is not so flawed as it might appear. Again, taking abjection as a tool to talk about a reality that can be described as structurally abjective opens up a register otherwise foreclosed to the analyst beyond the culture-nature dichotomy. Considering abjection as a primal, biological experience of entering discourse as well as one created and perpetuated by discourse may be circular, but it is not therefore false. If we think of it in Wynter's conception of being human, "hybridity" becomes key:

Once you redefine being human in hybrid mythoi and bios terms, and therefore in terms that draw attention to the relativity and original multiplicity of our genres of being human, all of a sudden, what you begin to recognize is the central role that our discursive formations, aesthetic fields, and systems of knowledge must play in the performative enactment of all such genres of being hybridly human. You will begin to understand, in the case of the latter, that the role of all such knowledge-making practices with respect to each genre is not to elaborate truth-in-general. Instead, the role of such knowledge-making practices is to elaborate the genre-specific (and/or culture-specific) orders of truth through which we know reality, from the perspective of the no less genre-specific who that we already are. These genre-specific orders of truth then serve to motivate, semantically-neurochemically, in positive / negative symbolic life / symbolic death terms, the ensemble of individual and collective behaviors needed to dynamically enact and stably replicate each such fictively made eusocial human order as an autopoietic, autonomously functioning, languaging, living system. (“Catastrophe” 32)

To me, this speaks to the use of abjection on two levels. Looking at abjection in its ontogenetic dimension, which Tißberger suggests is worthy of further consideration, I take from Wynter that we can read abjection as hybrid, both nature and culture at the same time. Not as one or the other, not as a switching or oscillating, but actually as one and the same - a hybrid existence that precisely does not differentiate between either. If we conceive of being human in bios/mythoi hybridity, there is no need to qualify whether we should view abjection as a linguistic, racial concept within a sphere of discourse that exists before the (allegedly non-raced) infant can abject, or as an (allegedly) naturalized part of a general humanity's condition articulated through the modern matrix that also prefigures the grounds of anti-Blackness (because it has been itself developed on those grounds). The element of hybridity in Wynter's conception makes it difficult to fathom in its entirety because it challenges the chronology of causality and logic that Tißberger applies to denounce the explanatory capacity of abjection as a critique of anti-Blackness. Where Tißberger criticizes the racial prefiguration of the concept as developed by Kristeva, following the urge to locate it in its ontogenetic existence for a general humanity at all is a fantasy of un-raced transcen- 
dence on the part of the scholar. Rather than being located somewhere, (antiBlack) abjection should be put to use as conceptual practice in terms of sociogeny, of eusociality.

Tißberger's most poignant criticism is that we can only talk about a subjectivity generated via "individual coherence," "wholeness," and "identity" when talking about abjection. This may be true, but the fact that these notions pertain to culturally specific Western concepts of subjectivity does not demand we renounce their power to explicate that very subjectivity. Any explication will certainly fall short for an elaboration of a generally racial tendency of a universally-conceived humanity - whatever that would look like and how (or why) one would wish to arrive at it - but it can be mobilized to consider the culturally specific anti-Blackness of the modern subject: the improvising subject as Man1 who "overrepresents itself as if it were the human itself," to use Wynter's phrase ("Unsettling" 260). We may not learn "why coherence and wholeness are so important that they are "produced instinctively" (Tißberger 48), but we can take these as facts regardless of their ontological quality. Also, with Broeck, we can use its capacity to give language to actions in terms of language and affect done by white subjects, who are abjectors by definition. While it may appear circular to critique the white modern subject from within, it is still the only available language this subject may understand. Wynter posits with Césaire "the study of the Word/mythoi" ("Catastrophe" 32) as a way to understand not only ourselves but our bios. Mythoi become an external ground from which we can see how our biological being exists. The language we use to discuss ourselves provides a way to understand ourselves. Through the study of the Word, we can avoid projective academic tendencies into nothingness (assumptions about generic and supracultural Human ontogenetic existence).

This conceptual bracket must be borne in mind through the rest of the project. When working with Winnicott's theory of play, for example, I reframe his conception of transitional objects as transitional Blackness, providing a culturally specific white jouissance of abjection and creating a subject-aeffect. This enables me to make statements about white subjects playing, and about why they are predominantly white in the case of improv. (To talk about Black absence in improv by looking at assumedly "ontogenetic" characteristics of Blackness is far from my mind.) Similarly, with Freud's theory of humor, I discuss the anti-Black violence of white laughter rather than laughter in general, and rather than analyzing Black cultural productions of humor. I have no interest in dissecting or analyzing those who do not hold white modern subjectivity, or speculating about whether abjection exists for them. I make no statements or assumptions about what might trigger a subjectoid-aeffect in those bodies precluded from what modernity knows as subjectivity or what their brain scans might look like. I 
do not apply abjection in a generally humanist project. I do not mobilize it to talk about people racialized as Black.

\subsection{Modern popular culture as Blackness}

Many scholars have considered, analyzed, and thereby performatively constructed a relationship between cultural production imagined as distinctly Black and an otherwise unmarked popular culture. The concept of cultural appropriation looms large in this academic field, and we clearly need a strategic and broadly applicable term to talk about how white people capitalize on (their performances of) Blackness. In the white supremacist system, white people emulate Black performance to become the Kings of Swing, Jazz, or Rock and Roll, capitalizing on styles, modes, sounds, and forms developed by artists racialized as Black. At first glance, this calls for the analytical tools of appropriation and authenticity. I do think that relevant, strategic, documentary, archival, and practical work can be done with these terms. A lot of academic labor has gone into the critique of white people capitalizing on Black forms and how Blackness has been misrepresented in popular culture. However, the rhetoric of appropriation cannot capture the foundational (libidinal, historical, structural) functions of (anti-)Blackness in what we know as a generalized popular culture. I argue it is ill-fated to consider popular culture writ large as a space for negotiation in which the appropriation or misrepresentation of Blackness can even take place. No "relationship" exists between Blackness and popular culture because modern popular culture is sui genesis the result of white abjectorship and the violent maintenance of a non-relation. The rhetorics of appropriation, misrepresentation, and authenticity interfere with a clear view of this structural ground. Virtually every aspect of global Western popular culture can be traced back to the sphere of Blackness as it comes about qua anti-Black abjection. Below, I consider the default lines of argument about appropriation and misrepresentation, showing that they fail to address the foundational anti-Blackness of popular culture. Then I turn to Saidiya Hartman to argue for a historicized view of the anti-Blackness of popular culture before I analyze it as a trading space for white affective stimulation through culturally specific modes of modern anti-Black abjection, engaging with Adorno's infamous jazz critique as an example. 


\section{Notes on the rhetorics of appropriation}

Appropriation is defined as "the process whereby members of relatively privileged groups 'raid' the culture of marginalized groups, abstracting cultural practices or artifacts from their historically specific contexts" (Dines and Humez 567) or the "taking - from a culture that is not one's own - of intellectual property, cultural expressions or artifacts, history or ways of knowledge," as in the 1992 resolution of the Writer's Union of Canada (qtd. Ziff and Rao 1). The language of appropriation always involves some sort of theft, an unlawful and unequivocal taking. Accordingly, the whole discourse around the term is ultimately one of property and property rights as they play out between cultures, about who has those rights and how their violation can be articulated or even sanctioned. Such an approach presupposes a Herderian understanding of culture, which relies on concepts of plurality and relations between cultures. Such relational plurality, however, cannot describe the non-position of Blackness within the white modern matrix. Despite their strategic workability, arguments based on appropriation fall short in articulating the complex and more fundamental issues at stake. Emerging from a romantic fiction of cultural relationality, they cannot provide sufficient traction to address the anti-Black popular culture at large. Debates about appropriation are at best superficial, at worst complicit in covering up the fundamental anti-Black abjection that constitutes both the historical ground and contemporary practice of popular culture.

To discuss this in more detail, a closer look at the logic of the appropriation discourse is helpful. Susan Scafidi theorizes cultural appropriation within the legal terms of intellectual property law because both presuppose an idea of intangible property. She assesses a "legal vacuum" when it comes to cultural group creation, whereby some forms of "creative [intangible] production receive extensive, even excessive, protection against copying under our system of intellectual property law," namely those that safeguard individual (intellectual) property. At the same time, cultural products are generally "indefinite works of group authorship, and they represent a particular challenge" for lawmakers (11). The allegedly paradoxical "legal vacuum" between individual and collective property rights is easy to understand in view of what constitutes a "group" within the matrix of the universalist global West, because it begs the question for whom respective property rights count. While laws are in place to protect the private and intangible ownership of individuals and privately-owned corporations, the same cannot be said for communal production or the collective ownership of intangibles such as cultural materials, knowledges, or styles. I suggest, therefore, that what presents itself as a "legal vacuum" in Scafidi's legal studies approach speaks to the lack of property relations between Western subjects and non-sub- 
jects who inhabit the sphere of Blackness - and not the lack of a legal grammar to address it. Departing from Scafidi, I believe that the legal and executive demarcation lines are not drawn between the individual and the collective. Rather, they are drawn between subjects with the capacity to own and those racialized as Black, who are thereby owned and constitute fungible, negotiable material to be accumulated (following Wilderson).

Echoing Wynter's critique of how modern Man "overrepresents itself as if it were the human itself" ("Unsettling” 260), the authors of "A Broken Record" remind us that Western culture is invisible to itself, despite being one culture among others:

The point about [Western] Culture is it is cultureless; its values are not those of any particular form of life, simply human life as such. The universalist self-understanding of Culture puts it in a relationship of superiority to 'mere cultures' as blatantly historical forms of life that value collective particularity. (Coleman et al. 180)

Misrepresentation and stereotypification are common critiques against practices understood as cultural appropriation. In the preface to Soul Thieves, Tamara Brown writes that "misrepresentation refers to deliberate, typically negative, depiction of a false ideal" commodified for capitalist gains (viii). The reproduction of negative stereotypes for capitalist gains comes across as ethically untenable. But as Scafidi's concept of an "identity tax" suggests (7), it also brings along the welcome idea of a cultural core, a communal source, a culture that can be violated in the first place. We can distort Italians by stereotyping them as Mafia bosses, poke fun at Germans by portraying them wearing white socks and sandals, and we can even produce derogatory images of First Nations because we think they have a particularly "savage" yet "noble" core. Such violations rely on a cultural locus from which claims can be made in defense of cultural material or even cultural truth. These gestures assume a potential authenticity, implying that there is a right way to represent a culture. While the law may not provide the instruments to sanction this sort of appropriative misrepresentation, an ethical code still applies. Here the notion of authority qua authenticity comes into play, which "may thus compensate for an inability to secure or protect ownership of an embodied idea, creation, or design" (Scafidi 53). Scafidi suggests that "in the unregulated, intangible world of cultural products, unenforceable assertions of ownership can instead take the form of 'authenticity", (53), or that "the rhetoric of authenticity performs much the same social function as property ownership, placing the claimant group in a position superior to all others with respect to the item in question" (54). Authenticity claims are thus like property claims without their political and financial ramifications. Scafidi finds the idea of au- 
thenticity "useful" because it "establish[es] source communities as the definitive repository of cultural meaning with respect to those [cultural, intangible] products" (53).

The notion of an authentically representable "source community" is the first instance where the rhetoric of cultural appropriation does not hold up in view of Blackness. Blackness does not and can never denote an authentic cultural source, always being open and vulnerable toward the white abjection that brought it about in the first place. The sliding signifier of Blackness does not denote a cultural core that the source communities envisioned by Scafidi can reckon with, which makes the "authentic representation" of Blackness impossible. Even recognizing it as a misrepresentable, appropriable "mere culture" is foreclosed to those racialized as Black. For abjected Blackness, there is no cultural core, no origin, no telos that can be envisioned within the matrix of white supremacy. Theorizing through the lens of intellectual property, Scafidi maintains that through its "Enlightenment parentage, it inherits a tremendous confidence in the ability of the rational mind to create, to solve, to progress, to assign value" (11). The absence of a cultural core inhabited by subjects makes it logically impossible to produce intellectual property from within the sphere of Blackness because neither intellectual capacity nor cultural authenticity is believed to reside there. The authors of "Broken Record" recognize the discursive function of "European intellectual property doctrines":

In the rhetoric that legitimates intellectual property, the aesthetic work, be it literary, artistic or musical, both embodies the personality of its individual creator and makes a singular contribution to human civilization, universally conceived. (Coleman et al. 180)

The idea of intellectual property is thus in itself raced. It restricts the realm of the appropriable to those with the capacity to produce and therefore to lose something in the first instance. Scafidi deals with "the intangible aspects of creations of the human mind" (14). Accordingly, the realm of the appropriable is restricted to those with the discursive capacity of performing a Human mind, that is, those groups that comprise what Wilderson calls the "race of Humanism," which is defined ex negativo by everything that is not Black, and by everything that the Black is not (20).

In terms of intellectual property, this means that there is nothing to appropriate because there is no locus of ownership. There is no space to be invaded, no culture to be raided, no individual's property rights to be violated - which does not mean there is no violence involved, but that there is no individual or collective subject against whom such violence qualifies as transgression. Consider this long excerpt from Nicholas Brady's article “Looking for Azealia’s Harlem Shake: 
Or How We Mistake the Politics of Obliteration for Appropriation" on his blog out of nowhere:

Appropriation depends on defining our relationship to objects through the lens of property relations, so that an object is the property of a person or group. This relation is always already thorny but is especially cut by cultural objects. Cultural objects can certainly be commodified, but the issue of ownership is always wrapped up in relations of power, privilege, and propriety [...]

If we are to talk about commodities and property in relation to culture, this should swerve us face-first into the topic of slavery and specifically the "human commodity" known as the slave [...]

The most horrifying to consider here is that the very happiness of the slave was owned by the master - this means the master often forced the slave to perform songs on the auction block, in the coffle to it, and for the slave to smile and laugh and joke in his/her presence (this is described as the "terror of pleasure" by Saidiya Hartman in her magnum opus Scenes of Subjection). This politics of appropriation can find its "origin" dispersed among the performance of domination we know as the peculiar institution. What we have called "appropriation" implies that black people own their culture and the master stole it from them. Yet, when we let go of romantic terms our claim sounds like this: a piece of property owns a piece of property and was stolen by the citizen who owns them both. How does a commodity own a commodity? How does the owner of that commodity steal a commodity from his own property? [...]

All that is to say that the concept of appropriation mystifies what is actually happening when white people "steal" black culture. Stealing implies a crime or a sense of wrongdoing or doing something improper. Yet the very concept of the proper - as well as property - depends on the black to be radically open to violation. So it is not improper to violate the black, it is in fact the definition of the proper itself.

Brady succinctly defines the radical consequences of the ways in which proprietary lens "skew[s] our ethical considerations" (Coleman 175). He mentions Hartman's Scenes of Subjection to discuss the flawed concept of appropriation in popular culture. I take his cue and read her multidimensional magnum opus as a call to historicize popular culture as always already Black and anti-Black at the same time.

\section{Historicizing the popular I: the auction block as the primal scene of US entertainment}

“[W]e are left to ponder," Saidiya Hartman writes, "whether the origin of American theater is to be found in a no-longer-remembered primal scene of torture" (Scenes 32): the coffle, the handling center of the enslaved and the space in which Blackness was created for a Euro-American commons. By trading Black bodies, the modern racialized order was performed through the materialization 
of who can own and who is owned. In the coffle, the racialized dehumanization of Black bodies was actualized qua performance. ${ }^{20}$ Yet the coffle was not only the space where Blackness was spectacularly theatricalized. It was also a theatrical event in its own right. Enticed purely by the entertaining qualities of the spectacle as such, an audience would show up with no interest in buying an enslaved body (or the financial resources to do so). The auction block was EuroAmerica's first popular theater stage. Even though it may function as one, this is not a metaphor. The aesthetic configuration of the coffle includes everything a theatrical situation demands: a stage, human-objects performing for an audience, costumes, director's instructions. Thanks to Hartman's immense archival work, there is no question about the entertaining amusements facilitated by and performed in the coffle. It is worth recognizing that the whole event was the performance of communal jouissance. The act of the cheerful Slave Jim Crow was only one element - the object of performance, so to speak - of the generally "festive atmosphere of the trade [that] attracted spectators not intending to purchase slaves" (Scenes 37). The auctioneers were no dry salesmen but entertainers themselves, "clown[s] [who] made funny talk and kept everybody laughing” (Carter qtd. in Hartman 37). The Black-racialized enslaved performers were given clothes by the stage-managing coffle driver "just before they reached the market space," who retrieved them after the show was over: costumes (Blassingame qtd. in Hartman 38). The theatrical presentation of the enslaved at times involved curtain-drawing and the presentation of musical skill or dancing abilities - both performed under the coercive direction of the whip. In its aesthetic and its political configurations, this was a casting in which white enslavers put together their ensemble to reenact white plantation fantasies for everyone, a communally shared event of staged anti-Black abjection. The organizers took advantage of the linkage between entertainment and selling refreshments, capitalizing on the anti-Black festivity as much as on the actual trading of Black bodies: "The distribution of rum or brandy and slaves dancing, laughing, and generally 'striking it up lively' entertained spectators and gave meaning to the phrase 'theater of the marketplace"” (Hartman, Scenes 37). It would thus be a mistake to think that the entertainment dimension was in any way secondary to the selling of the enslaved. While the business was the occasion, a good show was central to a vendor's success. Hartman quotes an 1853 article from the New Orleans Daily Picayune:

20 Here, I focus on the coffle's function as a reenactment of the original dehumanization that performatively actualizes that idea for the settlers. For the enslaved, this process started in their deportation. 
Amusements seldom prove attractive here unless music is brought to the aid of other inducements to spend money. So much is this the custom and so well is this understood, that even an auctioneer can scarcely ral[ly] a crowd without the aid of the man with the drum. (Scenes 38)

Euro-American encounters with enslaved Africans as presented on the auction block were theatrical, which gave birth to the idea of an all-American theater in "the theater of the marketplace that wed festivity and the exchange of captive bodies" (Hartman, Scenes 37). Here lie the origins of US American theater, popular or otherwise - and of the specters that haunt popular culture even today. The spectacularized staging of anti-Black abjection later transformed into the aesthetic theatricality of minstrelsy: shows performed by Black artists or white artists in blackface. Many scholars point out that minstrelsy founded US popular culture, especially in the fields of theater and comedy, and constructed Black figures for centuries to come:

Even as minstrelsy waned in popularity during the late nineteenth century, its impact continued to be felt. Blackface comics gradually disappeared from the American stage, but the stage black remained indelibly etched into the American mind until well in the twentieth century. (Watkins 102)

Hartman's focus does not lie exclusively with the dehumanizing aggression of those who killed and sold Africans, but with their audience. She conceptualizes the simultaneity of terror and pleasure of the auction block spectacle. In the initial chapters of Scenes of Subjection, she addresses how white subjects' alleged empathy for Black suffering facilitates musings on a generalized Humanity understood in the logic of its descriptive statement, which predetermines the subsequent symbolic and physical dehumanization of the Black bodies that enabled those musings. She considers abolitionist writing by John Rankin, an observer shocked by the goings-on at the coffle, and Abraham Lincoln on encountering a coffle on a steamboat. In fancying himself and his family in the position of those enslaved, Rankin seeks to make Black suffering legible by way of "facilitating an identification between those free and those enslaved" (18) in order to "make their sufferings our own" (Rankin qtd. in Hartman 18). In the very moment the white American enslaving subject extends their Humanity to what they know as a Slave, they are imagining a solipsistic endeavor through the signifier of Blackness - in this case their own fear of experiencing treatment "like a Slave." Pointing out how "in making the other's suffering one's own, this suffering is occluded by the other's obliteration," Hartman asks us to "consider the 
precariousness of empathy and the thin line between witness and spectator" that characterizes Rankin's abolitionist agenda: ${ }^{21}$

Rankin must supplant the black captive in order to give expression to black suffering, and, as a consequence, the dilemma - the denial of black sentience and the obscurity of suffering - is not attenuated but instantiated. (Scenes 19)

Another example is Lincoln's writing on his encounter with a coffle on a steamboat. Ruminating on the Human condition as such, Lincoln is confused by the apparent cheerfulness of the enslaved. He cannot fathom how "they were the most cheerful and apparently happy creatures on board" (qtd. in Hartman 34). Projecting his universalized idea of Humanity onto them, those in shackles seem to live in a paradox: "either their feelings seem unwarranted considering their condition [...] or this proverbial cheer especially suited them for enslavement." For Lincoln, "the elasticity of blackness [that] enables its deployment as a vehicle for exploring the human condition," provides the jouissance of reasserting his own full white Humanity at the peak of civilization (Hartman, Scenes 35). Empathy functions here as the white modern subject imagining themselves as a morally or ethically "good man or woman of one's kind" (Davis qtd. in Wynter, "Unsettling" 271), somatically ignorant of the fact that this specific kind has been brought about sociogenically by the same abjective praxis, and is grounded in the very matrical DNA that grants the white subject the capacity to perform such musings in the first place. Extending empathy in this way is to partake in the "overrepresentation of Man as if it were Human" (Wynter, "Unsettling” 267). However well-intentioned, such acts of abjective empathy are ultimately violent. Hartman mentions the term "abjection" only in passing, yet her argument resonates with Kristeva in that she reads terror and pleasure as drawing on the anti-Black matrix that creates a dehumanizing sphere of Blackness. These modes of abjection perform the same anti-Black sentiment and obliteration, ultimately uniting abolitionists and apologists of slavery.

21 White improviser Schleelein observes it is "such a fine line" for a white improviser to find a context in which the use of the n-word might be acceptable. Following Hartman, we can state that toeing the fine line that differentiates the abjector-as-witness from the abjector-as-spectator (both in action and perception) demarcates the start and end of white morality. In consequence, as a moral limit, this line also maintains morality in the first instance. In view of what I have been delineating as anti-Black abjection, this line is a discursive construct, which in performative practice is so thin that it nudges infinitely toward zero, towards nonexistence. Debating this line, asking what is right or wrong for a white subject to say or do, or performing regret that whatever a white subject does is always bad, maintains the moral stability of white supremacy. 
Analogically, white abjectorship gives rise to two different genres of Americanist theater aesthetics, both equally anti-Black: melodrama and minstrelsy. Hartman writes:

Despite differences between their respective conventions and stylistic devices, the uses made of the black body established continuities between minstrelsy and melodrama that surpassed their generic differences. Although the ethical valence of such violence differed, it nonetheless delivered a significant pleasure. Blows caused the virtuous black body of melodrama to be esteemed and humiliated the grotesque black body of minstrelsy. Uncle Tom's tribulations were tempered by the slaps and punches delivered to Topsy. The body's placement as ravaged object or as the recipient of farcical blows nonetheless established a corporeal language that marked Zoe, Tom, and Topsy as identifiably black and exposed the affiliations between the auction block and popular theater [...] Melodrama presented blackness as a vehicle of protest and dissent, and minstrelsy made it the embodiment of unmentionable and transgressive pleasures. (Scenes 26-27)

We need to understand (anti-)Black performativity within this historical trajectory, recognizing that anti-Black abjectorship transcends genre. We also need to recognize that anti-Blackness constitutes the origin of US popular culture as such - the culture that was to become globally dominant in the centuries to follow. There is no popular culture disconnected from this history, and there is no subversive position in popular culture that one may voluntarily chose to be "on the right side" of:

The terror of pleasure - the violence that undergirded the comic moment in minstrelsy and the pleasure of terror - the force of evil that propelled the plot of melodrama and fascinated the spectator - filiated the coffle, the auction block, the popular stage, and the plantation recreations in a scandalous equality. (Hartman, Scenes 32)

Recognizing the roots of US popular sentimental, humorous, and representational entertainment right there on the auction block and in the audience is consequential for contemporary scholarship on popular culture. If we consider popular culture structurally, as I propose, we need to think of it in its generic affective functionality rather than its particularistic meanings. Rather than seeking to decode Blackness within the grammar of unmarked white popular culture, I suggest we read popular culture as anti-Blackness in its aim to mobilize a certain affective (abjective) reaction for white subjects, namely the visceral wave, the experience of specifically anti-Black homeostasis developed above with Broeck and Kristeva as the culturally specific modern white subject-aeffect. However critically or romantically one may approach popular culture, it remains inextricably linked to its origins on the auction block, historically, libidinally, aesthetically, and financially: 
The relation between pleasure and possession of slave property, in both the figurative and the literal senses, can be explained in part by the fungibility of the slave - that is the joy made possible by virtue of the replaceability and interchangeability endemic to the commodity - and by the extensive capacities of property - that is, the augmentation of the master subject through his embodiment in external objects and persons. [...] Thus the desire to don, occupy or possess blackness or the black body as a sentimental resource and/or locus of excess enjoyment is both founded upon and enabled by the material relations of chattel slavery. (Hartman, Scenes 21) Historicizing the popular II: lynching parties and the spectacular nature
of Black suffering

+++ TRIGGER WARNING+++ To further discuss the racial extremes to which the libidinal structure of anti-Blackness leads and how it functions through the popular, in this section I engage with Baldwin's short story "Going to Meet the Man.” This literary piece includes several graphic descriptions and racist utterances by the white abjector in the narrative. Some descriptions are reprinted here to show how such (perceived) extremism relates to what is otherwise deemed harmless. I am aware that this intentionality does not circumvent the performative reiteration of reprinting; hence the trigger warning. +++ TRIGGER WARNING+++

From reading the auction block as the primal scene of US popular entertainment and spectacle, it is a short step to the entertaining qualities of lynching parties for white audiences well into the 1940s. The documentation and theorization of lynching and lynching parties in white supremacist culture have been prolific. I am concerned with its performative dramaturgy and entertainment quality, which have only been considered more recently. Contemporary theorization no longer reads lynching as a historically distinct cultural phenomena of the past but understands that its fundamental structures are still very much alive. In Legacies of Lynching, John Markowitz reads the practice in its function to create what he describes with Halbwachs as "collective memory" (xxi) from which a "cultural repertoire" (xxii) derives. He notes that before the Civil War, the term "lynching" denoted "a variety of forms of punishment, including beating, whipping, tar-and-feathering, and, only occasionally, killing" that mobs of American patriots inflicted upon "Loyalists and British sympathizers" (xxiii). In the antebellum years, "mob violence became increasingly widespread and was directed against abolitionists, Mormons, Catholics, and blacks." The primary victims at the time were white people who "held unpopular moral or social beliefs or who engaged in behavior that was deemed inappropriate" (xxiii). Anti-Black lynchings were rare exceptions, for example in response to rebellions of enslaved 
Blacks, or instigated by a general "extreme white insecurity" (xxiii). This rarity was not the result of recognizing the Humanity of Black-racialized people, but rather because lynching would have been conceived as property damage: "Slaveholders had financial or political stakes in protecting their slaves from lynchings." During and after the Civil War, however, "lynching" came to signify "putting to death" and was understood “"almost exclusively' as a method of punishment for newly enfranchised African Americans" (xxiii). Prior to the Civil War, then, lynchings functioned in the political realm, motivated by notions of law or morality. I suggest that when the practice became exclusively directed against formerly enslaved Blacks, such ethical or political negotiability loses ground, and the libidinal and symbolic functions take over to maintain the political sphere as such.

After considering traditional interpretations of what lynchings did and why they existed, Markowitz writes that "any explanation of lynching needs to account not only for explicitly political factors but also for economic and cultural motivations." The latter speaks to the notion of lynching parties as white, subject-making entertainment; parties varied in size but could grow into "massive public spectacles" that drew "thousands of participants" (xxv). Further, he lays out how lynching events must be read not only as spectacles in themselves but through their public announcements and documentation as well, through the selling of postcards (merchandise), ${ }^{22}$ journalistic coverage, and distribution through rapidly-developing technologies to reach even more people:

\begin{abstract}
The specific form that spectacle lynchings took became routinized over time. The standard sequence of events included a hunt for the accused, the identification of the captured African American by the alleged white victim or members of the victim's family, the announcement of the upcoming lynching, selection of the site, and the lynching itself, which involved torture and mutilation, often including castration, followed by burning, hanging, shooting, or a combination of all three. (xxvii-xxviii)
\end{abstract}

There were also "special trains to bring spectators to lynching sites that had already been announced, and they would occasionally advertise these trains in local newspapers" (xxvi). Lynchings ran on the collective libidinal fuel that drove the economy, politics, and entertainment industry. Markowitz argues that lynchings on the whole "were intended to create collective memories of terror and white supremacy" (xxvi). While this hints vaguely at the anti-Black structures of a given culture and its libidinal ground, speaking of intention endows

22 Many of these postcards have been collected and published James Allen in Without Sanctuary: Lynching Photography in America (2000). 
the organizers of these events with an agency and control over social meaning that I do not follow. Conceiving of these events as individually "intended" to keep Black-racialized people "in their place" in one way or another is pointless at best and dangerous at worst because it ignores the fact that it exists in the specific anti-Black configuration of an already existent libidinal structure. Reckoning with an active political or cultural intention requires the notion of a potential subjectivity for those racialized as Black. However, no such subjective position exists in the modern formations of sociality for Black bodies. Accordingly, it is less the scholarly classification of the functions and motivations of lynching parties than their literary treatment that takes us further here.

\section{“Like a far-away light:" Baldwin's “Going to Meet the Man"}

In "Going to Meet the Man," James Baldwin tells the story of a white deputy sheriff named Jesse, whom the reader first encounters lying next to his wife in bed at night. Jesse is sexually aroused but unable to have an erection, "silent, angry, and helpless," filled with excitement which "refused to enter his flesh" (229). Baldwin narrates a series of memories that lead Jesse further into his white supremacist anti-Black libido. It is a powerful piece, and I can only scratch the surface of all the meanings it entails, vertical, horizontal, and lateral. In this context, I read it as a psychological analysis, a discussion of the libidinal structure in which lynchings make meaning.

One of the remembered events is a lynching party Jesse attended with his parents when he was a young boy. Baldwin stresses at various points the festive and entertaining atmosphere of the event; the group they were going with looked "excited and shining" in anticipation, and they "were carrying food. It was like a Fourth of July picnic." As a celebration of national identity, the lynching event also provided an occasion for white people to meet and greet each other, not unlike the function of Sunday church. Jesse's mother "wanted to comb her hair a little and maybe put on a better dress, a dress she wore to church" (242). For Jesse, the whole family event and anticipatory sensations provided a feeling of comfort: he "got into the car, sitting close to his father, loving the smell of the car, and the trembling, and the bright day, and the sense of going on a great and unexpected journey" (243). His deeply ingrained and multidimensional comfort would from then on be linked to anti-Black abjection. The reader then follows Jesse through the event and learns about the harmonized affect generated in the crowd as they watch the burning of the Black body: "Those in front expressed their delight at what they saw, and this delight rolled backward, wave upon wave, across the clearing, more acrid than the smoke." (245) The crowd roared "as a man stepped forward and put more wood on the fire" (246). 
When, before castrating the victim, "one of his father's friends" caressed and played with a knife "brighter than the fire [...] a wave of laughter swept the crowd" (247).

Given this account, we can no longer understand lynching parties only as the vigilante projects of white supremacists in masks. These were public and popular events. Their organizers and stakeholders might have had little to no interest in putting the law back into the hands of white people in view of the advancing Civil Rights Movement. Like the festivities around the auction block or white minstrel artists and producers, people knew they could make money in producing these events. Because anti-Blackness is the lowest common denominator for all whites, it was a surefire way to attract the masses. We should thus conceive of lynchings in their affective function for all white subjects involved: the organizers, the actual murderers, the distributors, the advertisers, and most importantly the audience. For all of them, lynchings provide an affect of racialized and anti-Black national identity. Baldwin does not select a random date for the picnic: this is the Fourth of July. At a lynching event, the white subject undergoes the profound experience of collectively shared anti-Black abjection in its utmost extreme, and thus generates a powerful subject-aeffect of belonging to his symbolic kin: a collectively experienced reinvigoration of modern, American subjectivity.

For 8-year-old Jesse, this lynching event, and specifically the moment of castration, is formative. It provides a way of identifying with the celebrated collective abjector, who is doing the work for the subject (a configurative dynamic that comes up in the performance of bawdry, as theorized by Freud and discussed in the chapter on humor below). Jesse strongly identifies with the man who castrated the hanging body, wishing "he had been that man," who approached the "hanging gleaming body, the most terrible and beautiful object he had ever seen till then." His father's friend provided agency (into which the young boy could project himself) in a whole procedure that fetishizes the Black body's genitalia. Jesse takes in how his mother was "more beautiful than he had ever seen her, and more strange" (247).

Soon, young Jesse has sexual sensations (the first?) on his own:

The man with the knife took the [n-word]'s privates in his hand, one hand, still smiling, as though he were weighing them. In the cradle of the one white hand, the [n-word]'s privates seemed as remote as meat being weighed in the scales; but seemed heavier, too, much heavier, and Jesse felt his scrotum tighten; and huge, huge, much bigger than his father's, flaccid, hairless, the largest thing he had ever seen till then, and the blackest. The white hand stretched them, cradled them, caressed them. Then the dying man's eyes looked straight into Jesse's eyes - it could not have been more than a second, but it seemed longer 
than a year. Then Jesse screamed as the knife flashed, first up, then down, cutting the dreadful thing away, and the blood came roaring down. (247-48)

As the continuation of anti-Black dehumanizing abjective violence, lynching is a space where we can observe what Hartman terms the terror of pleasure and pleasure of terror in a highly sexual form. Baldwin's story repeatedly illustrates how anti-Black abjection creates a subject-aeffect through desire and fear or disgust. Seeking to overcome erectile dysfunction, Jesse's adult mind - consciously or unconsciously - draws on abjective fantasies, of which the lynching event is only the last. His childhood memory of the lynching festivity is preceded by the imagination of a "Black girl [causing] a distant excitement in him, like a far-away light." However, "the excitement was more like pain; instead of forcing him to act, it made action impossible." For Jesse's libidinal economy, there is no differentiation between a "black piece" being "arrested" or "picked up:" "it came to the same thing" (229-30). The specific modality of dehumanization is not part of the issue; both fall into the same affective function of anti-Black abjection.

The indistinction between fear or desire is further marked when Jesse goes on to think about encounters with people racialized as Black in his function as a deputy sheriff: "He felt that he would like to [...] never again feel that filthy, kinky, greasy hair under his hand, never again watch those black breasts leap against the leaping cattle prod, never hear those moans again or watch that blood run down or the fat lips split or the sealed eyes struggle open" $(230-31)$. The imagination of the Black girl does not have the desired effect, and Jesse's (unconscious) mind then brings him to recall a situation from work, in which he demonstratively beat up the "ring-leader" (232) of a group of Civil Rights activists to set an example. He shares his memory with his wife, but is unsure "whether she was listening or not" (thus in virtual solipsism):

He was lying on the ground jerking and moaning, they had thrown him in a cell all by himself, and blood was coming out of his ears from where Big Jim C. and his boys had whipped him. Wouldn't you think they'd learn? I put the prod to him and he jerked some more and he kind of screamed - but he didn't have much voice left. (232)

In remembering, recounting, and re-performing this narrative, "he began to hurt all over with that peculiar excitement which refused to be relieved" (232). Again, Jesse's sexual energy, cathected in the beating of the Black body almost to death, does not differentiate between fear or desire. I am reminded of Kristeva's dictum that fear is an "abortive metaphor of want" (35). After beating the boy unconscious, Jesse "was shaking more than the boy had been shaking. He was glad that no one could see him. At the same time, he felt very close to a very peculiar, 
particular joy; something deep in him and deep in his memory was stirred, but whatever was in his memory eluded him" (233). Baldwin pushes the abjective force to its logical extreme: just as he is walking to the cell door, Jesse is addressed by the young Civil Rights leader he thought to be unconscious, and "[for] some reason, he grabbed his privates" (233). He then performs antiBlack abjection of an already apparently dead Black body. Because the boy is unlikely to talk back any more, and because there is no audience, this abjection is an entirely autopoietic, solipsistic phenomenon (much like recounting it to his tuned-out wife) that provides a subject-aeffect ending in involuntary sexual arousal.

Now the boy looked as though he were dead. Jesse wanted to go over him and pick him up and pistol whip him until the boy's head burst open like a melon. He began to tremble with what he believed was rage, sweat, both cold and hot, raced down his body, the singing filled him as though it were a weird, uncontrollable monstrous howling rumbling from the depths of his own belly, he felt an icy fear rise in him and raise him up, and he shouted, he howled, "You lucky we pump some white blood into you every once in a while - your women! Here's what I got for all the black bitches in the world-!” Then he was, abruptly, almost too weak to stand; to his bewilderment, his horror, beneath his own fingers, he felt himself violently stiffen - with no warning at all. (235)

This passage eloquently crystallizes much of Baldwin's narrative as well as my argument so far: the cold and hot sweat, the singing Jesse sought to stop that suddenly comes from his own belly, the fear rising inside that raises him up. None of this is voluntary. There is "no warning at all" for these affects. Not only is it involuntary; it is also to some degree incomprehensible for the white subject personified by Jesse. His feelings and sensations are not for him to understand; "whatever was in his memory eluded him" (233), and he can talk only superficially about "what he believed was rage," and a generally "obscure comfort" that comes with certain songs he hears (235). Jesse, the white subject, does not understand the language of his libido, the grammar by which he lives.

In an example of pure and almost textbook anti-Black abjection, he then puts on an imagined blackface. Jesse - whom the reader has followed as he ponders various dehumanizing modes of gratuitous violence, both symbolic and utterly reality - ultimately overcomes his erectile dysfunction by imagining himself in terms of the very Blackness he abjects:

He thought of the boy in the cell; he thought of the man in the fire; he thought of the knife and grabbed himself and stroked himself and a terrible sound, something between a high laugh and a howl, came out of him and dragged his sleeping wife up on one elbow. [...] He thought of the morning and grabbed her, laughing and crying, crying and laughing, and he whispered, as he stroked her, as he took her, “Come on, sugar, I'm going to do you like a [n- 
word], come on, sugar, and love me just like you'd love a [n-word].” He thought of the morning, as he labored and she moaned, thought of the morning as he labored harder than he ever had before. (249)

The libidinal economy of the modern Western subject plays out through the sexual sphere of subject-aeffects, always grounded in the anti-Blackness that stimulates it. The white subject's simultaneous destruction of and desire for Blackness is central in this continual procedure, which is why "white people fuck on-screen to black music and not to their own," as Wilderson notes (Williams and Wilderson, par. 115). Wilderson makes the instructive point that while everyone knows intuitively that this is true, it remains intellectually difficult to grasp for many:

I think everybody in this country and everywhere I've been in the world wraps their heads around it intuitively, which is why blackness is so energizing, whether it's negrophilia or negrophobia. The energizing capacity of blackness is just infinite because it's this locus of violence from which respite cannot even be theorized. (par. 118)

Blackness enables the white subject to experience itself in a way that feels true, real, and coherent - symbolically, libidinally, sexually. For the white subject, Blackness "authenticates the orgasm, a kind of pure jouissance" (par. 118).

\section{"Now put on this noose:" improvising the cultural repertoire}

In its extreme configuration of fear/desire, lynching is a part of the US entertainment industry's repertoire and provides what Goddard and Wierzbicka call a cultural script. As developed and applied in the field of pragmatic linguistics, a "cultural script" is "a technique for articulating cultural norms, values, and practices in terms which are clear, precise, and accessible to cultural insiders and outsiders alike" (153). They write:

Aside from the semantics of cultural key words, other kinds of linguistic evidence which can be particularly revealing of cultural norms and values include: common sayings and proverbs, frequent collocations, conversational routines and varieties of formulaic or semi-formulaic speech, discourse particles and interjections, and terms of address and reference - all highly "interactional" aspects of language. (153-54)

Although Goddard and Wierzbicka are primarily concerned with linguistics, we should not hesitate to read culture as text here and understand the explanatory power of a concept like a script for culturally specific signification. They also position the concept within a broader field of ethnopragmatics, which resonates with Sylvia Wynter's work. The use of cultural scripts in communication will 
also, by necessity, provide a sense of being "a good man or woman of one's kind” (Davis qtd. in Wynter, "Unsettling” 271). In the context of anti-Black lynching, we must reckon with the fact that, in mobilizing the "spectacular nature of black suffering” (Hartman, Scenes 22), lynchings engender, articulate, and make manifest a popular culture that already exists as a libidinally (politically, legally) shared ground, representing a norm rather than an exception. They are to the popular as common sayings are to language. Both share the performative pars pro toto logic of knowing/speaking, ensuring that the speakers know where they belong and providing them the sensation of a subject-aeffect. In addition, lynchings communicate to the outsiders (to Humanity) racialized as Black in "clear, precise, and accessible" terms (and experiences). Because the script of lynching is not so much part of but effectively built into the notion of the popular culture as we know it today, it can be intuitively activated anytime - be it in concrete action, representational arts, or displaced metaphor - with full white integrity:

I did a show recently in which a guy initiated a scene with me. He was a white male. He initiated the scene by, "Ok, now put on this noose." And I was like "Whoa, in real life how would I respond to this?” And I was like “Hey, I don't think” - because he was my father - "Hey father, I don't think you're being really sensitive to my cultural background, so I am not gonna do this." It was a response in character but also like, "How would I as a human in this situation respond to this?” It's yes and...! But you can yes-and something without dooming it. This was furthering the scene to a point. I don't have to comply to this theme that I think is not nice. I personally don't invite friends and family to my improv shows. I invite them to sketch shows where I know what is about to be said but improv? No. Eight weeks of shows - I am not inviting anyone because I know what can happen on stage. And then this one time, when a friend came, this lynch thing happened. (Perkins, personal conversation)

I will return to this anecdote, but here I only want to point out that the symbolic violence on the improv stage in this scene is a central - if superficial - aspect of how improvisers ensure that improv maintains a white space. As white as actual lynching sites and the towns or cities in which they take place - as in Baldwin's "Going to Meet the Man," when 8-year-old Jesse, driving with his family to the lynching party, realizes that

he had not seen a black face anymore for more than two days [...] there were no black faces on the road this morning, no black people anywhere. From the houses in which they lived, all along the road, no smoke curled, no life stirred - maybe one or two chickens were to be seen, that was all. There was no one at the windows, no one in the yard, no one sitting on the porches, and the doors were closed. [...] They passed the [n-word] church - dead-white, desolate, locked up; and the graveyard, where no one knelt or walked, and he saw no flowers. He wanted to ask, Where are they? Where are they all? But he did not dare. (243-44) 
In an unsettling analogy with the improviser curious about the absence of Black "life" or the fact that the Black church has turned "dead-white," Jesse lacks the courage to ask this question; he knows somehow that the answer lies in the structure of the situation, in what can be anticipated. For Black people, improv is less a safe space than one in which danger openly lurks, because collective entertainment centers around the symbolic, real, and symbolically real dehumanization, killing, burning, and castration of Black-racialized individuals. Choosing or advising others to stay absent is different than allegedly being insufficiently “cosmopolitan,” as Roger Bowen has it (qtd. in Sweet 40). Many will (intuitively) deny a connection between anti-Black lynching parties and an improv scene, but the anti-Black dynamics are the same, and the abysmal performance of a lynching reenactment (or the suggestion of one) only takes what is always already present in other forms of staged entertainment to its logical extreme.

\section{Historicizing the popular III: minstrelsy}

I now turn to a more widely-accepted understanding of the role of Blackness in popular culture. Mel Watkins's On the real side is an extensive history, an invaluable archival work, and a multifaceted approach to Blackness, comedy, and US popular entertainment. Despite our conceptual and axiomatic differences, his work is highly informative and provides ample points of reference for my project. ${ }^{23}$ Watkins notes that, when Black performers entered the popular stage, “a

23 In view of the above theorization of critiquing the modern West, Blackness has not incidentally become attached to these significations. Watkins's extensive work engages with the question of humor within Black communities and the assumptive ascriptions made by white people towards Black humor and Blackness in general. His study "traces and examines the social functions of two disparate strains of humor: the often distorted outside presentation in mainstream media (initially by non-Blacks) and the authentic inside development of humor in Black communities (from slave shanties and street corners to cabarets) as well as in folklore and Black literature, films, and race records" (41). In this endeavor, Watkins presents a grand effort to isolate African elements of humor on the plantation. He provides ample evidence to understand the ingenuity and intelligence with which slaves adopted social masks, using humor in communicative functions that would exceed the white masters. In so doing and by necessity, the enslaved had from the very first moment a clearer understanding of the social configuration - and humor may have been a way of coping. Watkins quotes Ellison: “We couldn’t escape, so we developed a style of humor which recognized the basic artificiality, the irrationality, of the actual arrangement" (33). Watkins argues within the terms of influence: "it is the expressive manner of African-American humor that, second to music, has most influenced mainstream America's popular culture" (48-49). In this project, I am concerned with how Blackness is a structural necessity for the emergence of popular entertainment, rather than suggesting ways in which it influenced 
distorted black spectre already dominated the stage" (123). He addresses how Blackness serves as the ground for all American US entertainment, easily overwriting all the stock characters of humor European immigrants brought from their home nations: "blackness was associated with humor almost from the outset [...] but it was not until the early 1800s that [Black characters] began to emerge as principle figures in America's comic lexicon.” Other comic types, whether regional or of other ethnicities, were slowly replaced by "black-faced caricatures" (82-83). While several white actors and clowns imitated (their interpretation of) Blackness in the 1820s, Thomas Rice's blackfaced stage persona became the biggest success. Advertised as "Jim Crow Rice," he "became one of America's best-known comedians." Rice's and other shows ensured that "[b]y the 1830s, blackfaced white performers were one of the most popular attractions on the American stage." By the end of that decade,

through refinement and more determined exploitation of the subject, blackfaced characterization had virtually eliminated all other ethnic or regional types. "Jim Crow," the unkempt ignorant plantation slave, displaced the backwoods or Frontier caricature; and "Zip Coon" or "Jim Dandy," the bombastic dandified city slicker, replaced the Yankee character as America's central comic figures. (Watkins 84-86)

The overriding of European characters by Blackness represents how Americans unified qua Blackness in their distinction from their European legacy. Though by no means unknown to modern Europe, the anti-Black abjective aesthetics of minstrelsy were mobilized to create a unique national self-understanding of Americanness via a generalized yet specifically (anti-)Black popular entertainment. To be a "good man or woman of one's [North American] kind" (Davis qtd. in Wynter, "Unsettling” 271) was not connected to or involved in or part of this culture - it was it. ${ }^{24}$ When the white American subject imagines its social

it. How exactly this happened and what specific comedic strategies were used to what ends is not for me to discuss - mainly because the vector of this inquiry would throw me into the ethnographic trap. I would necessarily fall victim to the white "misinterpretation of slave behavior," that was, according to Watkins, the ground for Black humor to emerge.

24 Notably, theatrical entertainment at that time "included not only a full-length play but an assortment of variety acts" (Watkins 85). These shows were "consciously low-brow entertainment [that] emphasized the spectacular and the bizarre" in a "raucous, sensational, and often profane atmosphere of popular American entertainment during this period" (86). Because "for Northerners, in particular, blacks were still seen as curiosities," blackface performances of white dehumanizing imaginations soon became part and parcel of the entertainment per se. They were intricately bound up semantically with the experience of jouissance in collective, popular, anti-European self-assurance through laughter in the aesthetics of theatrical representation. 
and political distinction from Europe, the ground and motorizing energy for this political negotiation is Blackness, and its libidinal and aesthetic mode is antiBlack abjection.

Here I want to consider the genesis narrative of the first fully-fledged blackface minstrel troupe, though I maintain some distance from Watkins's notion of accidentality and his primarily economic framework:

As with many events in American cultural history, the establishment of the minstrel show as a separate form of entertainment was accidental. America had experienced a financial panic in 1837, and in the early 1840s, the nation still reeled near the brink of financial disaster. Unemployment was rampant, and even among variety performers, jobs were hard to find. Seeking a solution to their own financial problems, four out-of-work white performers met in a New York City hotel in 1842 - a year that some historians described as the "nadir" of the theatrical scene. The men [...] all had previous experience as blackface entertainers. [...] The idea [to form a troupe and concentrate exclusively on blackface mimicry], while certainly opportunistic, was no more than a pragmatic solution to their immediate problems. They were unaware that they had stumbled upon a notion that would transform American entertainment and firmly establish the image of blacks as happy-go-lucky plantation darkies and outrageously dressed, ignorant dandies in the entertainment media. (81)

Rather than engaging with the contingency of the historical situation or reckoning with the economic pressures these white men faced before they came to fame as the Virginia Minstrels from 1843 onwards, I highlight the ease with which they could decide to "concentrate exclusively on black mimicry" because anti-Black abjective discourse and affect were readily available to them. Because its success was already there, Blackness already was popular comedic culture in the form of the auction block spectacle, before "entertainment culture" existed as understood today. There were no political or ethical boundaries, and a white community of laughers could safely be counted on because Blackness already existed for the white public's enjoyment. Anti-Blackness provides the structural ground, the semantic field of psychosocial abjection, on which the US entertainment industry was and is based. Minstrelsy did not accidentally happen to emerge in the "nadir" of the theater scene but galvanized the anti-Black forces structuring popular culture that were always already there. As a nationalized form of entertainment, "America's popular culture signature piece" was much more than lowbrow entertainment (Kopano 5). Quite the contrary, in their enjoyment of minstrelsy, the working class could feel aligned with the higher levels of society on the grounds of their shared skin color. By 1844, "this new entertainment genre had so swept the nation, that the Serenaders were invited to the White House to perform for the 'Especial amusement of the President of the United States" (Watkins 88). This form of popular culture did not merely provide meaning to the notion of a white working-class (or the grounds for its creation in Eric 
Lott's sense), but facilitated national cohesion. Minstrelsy posited a vital, democratic American man, invigorated by Blackness/blackface and distinct from the degenerate lifeless figures of Old Europe. (The same logic of distinction from Old Europe remains visible in the celebration of improv as an All-American art form as will be discussed later.)

Given its cohesive power, Watkins perceives minstrelsy in a period of nationalist crisis as a racial contact zone - a space of potential sociopolitical negotiation, which debatable position Eric Lott also holds. Watkins argues that during the superficial "rift" that was abolition, minstrelsy as national popular culture mobilized the essence, the affective ground of its success, and turned towards the overt abjective dehumanization of Blackness that had always libidinally structured it:

Confronted with a choice of preserving the Union or supporting black Emancipation, [minstrel acts] soon eliminated all but the most servile and disparaging images of blacks from their shows. From about 1853 to the Civil War, then, nearly all vestiges of black humanity were excised from minstrel performances. During this period the portrait of the plantation was made even more idyllic, and the stereotype of black males as childlike, shiftless, irresponsible dolts was heightened. Freed blacks, in particular, came under pointed attack. They were invariably pictured as inept, hopelessly inadequate souls, who longed for the guidance of white men and the security of the 'ole plantation,' or, perhaps worse, near-bestial reprobates who, after disastrous consequences, foolishly took on 'white' airs and lusted after white women. The comic, degrading image of blacks had almost reached its peak. America's most popular entertainment form had become a forum in which white performers posing as blacks actively lobbied for the continuation of slavery by presenting degrading, consciously distorted comic stereotypes intended to 'prove' that slavery and black subordination were justified, or, even more insidiously, to demonstrate that blacks actually preferred serfdom. (94-95)

Preceded by the auction block and followed by popular lynching events, minstrelsy was a formative genre in the creation of popular culture, going far beyond the notions of making a white working class that Lott suggests. It riveted Blackness into the national unconscious, generating a space that allows white people not only to use, apply, and capitalize upon it, but also to relish, savor, and consume it. Even Watkins, in view of his recurring reference to historical contingency, is quite clear and mobilizes the trope of public property:

Of course, the Sambo stereotype began long before minstrelsy. [...] But the popularity of the minstrel shows heightened its acceptance and riveted it into the national consciousness. By the 1880s, that image had become public property [...] Americans who detested flesh-andblood blacks relished the minstrelsy-inspired caricatures that flooded the country. Minstrelsy made Sambo as American as apple pie. (102-03; emphasis mine) 
However, minstrelsy was more than "the heart of 19th-century show business" (Tosches 11). It also set up a libidinal space in which white modern subjects could fantasize about the transcendence of what they perceived as the boundaries of their sociopolitical existence, their reduction to rationalism as determined in their ratiocentric descriptive statement. Burnt cork on the face was a vehicle for circumventing the restrictions of a self-imposed civilized (as opposed to natural) self-image, both for professional and amateur performers and for their audiences:

Whether literally as a performer, or figuratively as an observer, "the white man who put on the black mask modeled himself after [...] a black man of lust and passion and natural freedom." He thereby not only indulged the desire to escape the binds of "civilized" behavior but also affirmed his superiority. (Watkins 100)

Blackness here functions as a portal for white flights of performative excellence, that is, being very good men of their kind, which white subjects (felt they) were unable to do without the comic cork. Watkins shows how the jouissance experienced in the audience was most likely shared by the actors on stage: "The cloak of blackness apparently allowed them to cast most of their own inhibitions to the wind, thereby heightening the excitement and frenetic pace of their performance [with] exuberance and vitality" (87). Anti-Blackness created clowns and provided the somaesthetic transcendence of the self through a culturally specific mask. Blackface also paved the way for an amateur theater scene, allowing anybody to perform per the egalitarian and democratic ideals of the republic. The abjective jouissance of partaking in blackface performance lured actors onto the amateur stage. By the turn of the century, "'every city, town, and rural community had amateur minstrel groups”' (Boskin qtd. in Watkins 99). In 1930, Carl Wittke, "an unabashed minstrel enthusiast," lamented the disappearance of the American minstrel show "except as a vehicle for amateurs” (qtd. in Watkins 98). AntiBlack abjection articulated through blackface was an easy way for white subjects to become amateur actors.

In our engagement with popular cultural practices, we must keep in mind that however universal or generic popular culture may seem, it has always been "uniquely African-American in origin, conception, and inspiration" in all its styles and modes (Tate 2). Like the early traders of enslaved Africans and plantation owners, the players in the field of popular culture would violently acquire "black bodies [that] would be responsible for providing the labor and natural resources that would propel all of the Western powerhouses to their global supremacy" (Kopano 4): 
Everything about African-Americans - their bodies, dances, songs, dialects, passions, worldview, and so on, real and especially as imagined by whites (and, eventually, imagined by other blacks, too) - became the base material for the popular entertainments that matured into mass culture. The black condition became a canvas for projecting all that the whiteness ideal sublimated; black cultural output became the paint. (L. Wynter 22-23)

In view of the above discussion of the auction block, lynching parties, and minstrelsy, it must be conceded that there is an overt and not particularly subtle continuum of dehumanizing anti-Blackness in the making of the popular and its culture as such. Minstrelsy is not a distinct phase of popular culture, but its ground. Minstrelsy provides the occasion, the aesthetics, the content, and everything else to modern US theatrical entertainment. It is the brick and mortar of a popular wall that may be painted or scribbled on, but will always function as the border of whiteness. Whenever white subjects seek to reassert ourselves through the popular, even in imagined opposition to it, whenever we feel drawn to (consume) popular culture, we are drawn to (consume) Blackness. When we are active in popular culture, we are putting on a "cloak of Blackness" in one way or another (Watkins 87). And it does not stop here. The anti-Black fabric of popular culture predetermines the way it has traditionally been theorized, as I will consider in the next section.

\section{Theorizing the anti-Black popular}

Current academic interest in popular culture tends to meander between two positions: on the one hand, a romanticized fascination with its (assumed) subversive potential that celebrates the possibilities of more or less radical oppositionality (whether aesthetically or politically framed, temporarily realized or imagined utopias); and on the other, as the capitalist top-to-bottom infiltration of hegemonic knowledges into an assumed political unconsciousness of the people (whom exactly?) via a panis et circenses-cultural industry (and subsequent differentiation between high and low art), most prominently developed in the work of Adorno and the Frankfurt School. These positions resonate with the simultaneity of fear and desire, terror and pleasure to which the anti-Black ground of popular culture gives rise. Metatheoretically, it is not farfetched to interpret both as libidinally motivated in order to generate a subject-aeffect. Consider Jackson's assertion that the Blackness of the field drives scholarly endeavor:

[I]t could be conjectured that one of the main reasons "popular culture" has become a category for inquiry has been the enormous success of hip-hop culture and its component performance domains, rapping, graffiti writing, break dancing, emceeing, and deejaying. A 
huge intelligentsia - scholars, television and newspaper journalists, museum curators, a wide range of artists, hip-hop magazine cultural critics, and filmmakers - has been seduced by hip-hop's growth and vitality. Hip-hop has played a role in establishing the field of black mass cultural studies. (23)

Engaging with a phenomenon like hip-hop culture on academic turf does not happen outside the affective register. Quite the contrary, when performed by a white scholar, dealing with Black cultural material is in itself the performance of anti-Black abjection that ultimately reasserts the white scholar as subject and obliterates the object in a kind of culturally specific logorrhea. While this critique can certainly be directed against the present project, it is especially true if the academic gesture stands in the ethnographic tradition, using its methodology or applying its axiomatic logic - which also involves the mobilization of concepts like authenticity and appropriation. This is especially difficult to grasp for those with a positive, defensive, or apologetic view of popular culture, who assume that, with the help of popular cultural material and the analysis thereof, the differentiation between low and high art can be overcome.

\section{Shusterman's romance}

In "The Fine Art of Rap," Richard Shusterman - who "likes the music" and thus has "a personal stake in defending its aesthetic legitimacy" (201) - addresses the qualities of rap, arguing that they satisfy "the most crucial conventional criteria for aesthetic legitimacy" (202). In his discussion, he applies the postmodern toolbox and draws on the modern modalities of intellectual autonomy. As wellmeaning as he may be, and as progressive as his approach may appear, it pretends to (temporarily) lend subjective capacity to Blackness qua white scholarly authority, which must always remain at the mercy of the master-scholar. Additionally, it assumes that an aesthetic-scholarly legitimization within white academic institutionality is in some way desirable for a cultural scene that has no stake in it or anybody else. Both aspects position the argument in a feigned register of negotiation that is in actuality foreclosed to Shusterman's object itself. His treatment of rock music in "Animadversions on the Critique of Popular Art," which pits the somatic aesthetics of rock music against intellectual highbrow-treatment, is a similarly racial celebration of Blackness-as-popular culture. He writes:

Rock songs are typically enjoyed through moving, dancing, and singing along with the music, often with such vigorous effort that we break into a sweat and eventually exhaust ourselves. And such efforts, as Dewey realized, involve overcoming such resistances as "embarrassment, fear, awkwardness, self-consciousness, [and] lack of vitality" (Dewey 
1987 [1934]: 162) [...] The term "funky," used to characterize and commend many rock songs, derives from an Africa word meaning "positive sweat" and is expressive on an African aesthetic of vigorously active and communally impassioned engagement, as opposed to dispassionate, analytical remoteness. The much more energetic and kinesthetic aesthetic response evoked by rock exposes the fundamental passivity underlying our established appreciation of high art. (111)

Shusterman deploys the term "funk" from jazz parlance in this argument about (the largely white phenomenon of) rock music. ${ }^{25} \mathrm{He}$ makes violently homogenizing assumptions about the unified aesthetic of an entire continent, pitching "passion, sweat and energy" against a European "dispassionate analytical remoteness" and thus vigorously remains within the axiomatic logic originating in the Platonic postulate, transumed in the theocentric statement of Heavens and Earth, and turned into the racialized dichotomy between High Reason and irrationality, between intellect and sensuality. In Shusterman's work, we can observe that such a positive affirmation of popular culture's sensuality is only possible qua racialized reference to the specific Blackness of popular cultural production. This is not his fault - the register of morality is not helpful here but is instead a discursive predisposition of the system in which popular culture exists as Blackness without being called so. If we want to argue in favor of popular culture, we have no alternative to applying the racial register of its Black physicality, baseness, earthiness, affect. ${ }^{26}$ We can further substantiate this position by considering how other (unfavorable) treatments of popular culture draw on the same register: Those who despise it do so on the same argumentational ground. Where Shusterman cherishes the danceability of rock music as an almost transcendental experience, this is also at the center of Adorno's infamous jazz critique. Where Shusterman's theory is structured by desire for Blackness-asPopular Culture, fear speaks through Adorno's. And both perform a dazzling dance on the (non-existent) thin line between the witness and the spectator.

25 I want to note not only that rock music is predominantly a white, male phenomenon, but that its entrance into popular culture is linked to processes of Black cultural production's obliteration, as Waksman and others recognize.

26 I hope it has become clear that this discursive dimension is not superficial or detached from the real world. This entire chapter has argued that popular culture's discursive dimension and its racialized rhetorical repertoire are entirely grounded in traceable historicity, numerous realworld performances, and their contemporary variants. This is not a matter of interpreting the popular, but of reframing it in its historicity and cultural specificity. 


\section{Adorno's Querfront}

Adorno's treatment of jazz has been much discussed, attacked, and defended. However, to get a grip on the incommunicability between scholar and object and the surprising consequences that follow from his line of argument, we must not only take his theoretical context very seriously but also reckon with the racial dimension and libidinal terminology he applies. Adorno's racism cannot be excused; we can neither bracket instances of overtly racial language out of an otherwise valuable jazz critique nor cut that critique out of an otherwise valuable critical framework. The racialized components of his analysis are not accidental; his allegedly objective musicological arguments only operate when substantiated and substantialized by anti-Blackness. If, as I have argued, popular culture is made up of Blackness in its modes, material, and the affective structures it mobilizes, then what Adorno has to say within the anti-Black register will have some bearing on this register. I therefore read his racism and his antiBlack rhetorics as symptoms of the foundational structure and libidinal investment in his critique of popular or mass culture and the cultural industry at large, which was a project designed to re-install modern subjectivity as such the Human of Humanism - after the atrocities of World War II.

After decades of superficial debates between musicological justifications ("It is true that jazz musicians did not invent novel harmonies!"), blunt accusations that Adorno is ignorant of the "social" dimensions of jazz ("It is important for the Black community!"), aggressive positions on moral grounds ("White people must (not) be allowed to speak negatively about Black cultural production!”), and defenses of jazz on equally racial grounds ("Adorno might not like it, but I appreciate Black performers expressing their wildness!”), in recent years the engagement with this complex has matured. Suggesting that "all the cards in this game have been played," Eric Oberle regards Adorno's jazz critique as a "wound” in the latter's critical oeuvre. Oberle reads this "wound" symptomatically, not unlike the punctum methodology I apply in this project, given that "the wound of jazz is defined by problems of race, culture, identity, violence, and discrimination.” Oberle positions Adorno “among the twentieth century's pioneering critics and analysts of racism and cultural bigotry," and finds that his treatments of jazz stand in paradoxical relation to the rest of his work (365). Oberle has "no doubt that the jazz question must be taken seriously as a limitation that reflects much about Adorno, both biographically and as a philosopher, sociologist, and cultural critic" (365). In terms of a more mature engagement with Adorno's criticism, Oberle suggests relating what he refers to as "conceptual issues" to "the problems they were hoping to solve, and to how those ideas necessarily struck against their limits - limits with which the individual thinker had difficulty, 
and which he could do little else but to internalize" (365). ${ }^{27}$ However, he does not provide the ultimate guide on how to read Adorno's relationship with jazz constructively. There are, in fact, some cards yet to play (and presumably several more not covered here). Fumi Okiji's Jazz as Critique: Adorno and Black Expression Revisited is the most instructive discussion of the subject. The author brings to the table the musicological expertise of a professional jazz performer, the scholarly acuteness of the critical theorist, and the competency to talk about the functions of Blackness meaningfully. No more does she ignore the racial rhetoric of Adorno's critique but takes on a different argumentational direction by suggesting that Black existence and the cultural production emerging from it are always already "critical" of white modernity:

\begin{abstract}
Blackness may well be a thing not yet known, as Fred Moten tells us, and it is unclear how the world could ever know it without internal collapse. But black life is lived, and particularly where it comes up against its appropriated and sanctioned mainstream images and uses, where it misshapes the categorical smoothness of race, it provides valuable insight. In its contradictory subjecthood - human enough for governance but too black for admittance in the "household of humanity"- such life rhymes with what Adorno understands as the double character of radical art, rejecting what it is unable to rid itself of through critical immersion. [...] What is suggested here [...] is that black expressive work cannot but help shed light on black life's (im)possibilities. (4)
\end{abstract}

According to Okiji, jazz is not only "capable of reflecting critically on the contradictions from which it arises [but] it is compelled to do so" (5). Throughout Jazz as Critique, and drawing from a wide range of Black theorists (most centrally Du Bois), she demonstrates convincingly that jazz can indeed be argued to perform Adorno's aesthetic demands for subjective and aesthetic resistance - precisely because of its Blackness. This argument assumes Adorno's ignorance both of "the principles of structuration in jazz work" and of "black sociohistory" (12). Okiji sets out to order and qualify the discussion. Even though her approach is highly instructive, I do not go down this path because a) I see no need to legitimize either Adorno or jazz, b) I wish to avoid staying within the register of negotiation and resistance as developed by Adorno, and c) I cannot add to what Okiji says about jazz practice. For the remainder of this chapter, I will work with her insight occasionally but not instructively.

27 Oberle theorizes of twentieth-century "identity" and a "wounded political subjectivity of the modern era" (357). As I am not interested in reading Adorno's critical theory at large, especially in view of the white, Human disposition of wounded-ness of a universalized subject, I will not engage with his text in more detail. 
Adorno did not mistake white commercialized swing for "real” jazz, but was aware of the development of bebop and "oppositional groups" ("Fashion" 122). ${ }^{28}$ However, for him, all jazz is primarily a "type of dance music" (45), "musically completely banal and conventional" (67), and all of its variants are governed by the same aesthetic principles, which never fundamentally break the "harmonicmelodic convention of traditional dance music" ("On Jazz" 45). Syncopation is presented as jazz’s rhythmic structuring principle. Accordingly, we can deduce that when Adorno speaks about jazz, he also means rock and roll and any other kind of popular music before and after. He inflates jazz to encompass all popular music. ${ }^{29}$ He follows the same logic when addressing the device of vibrato:

[Jazz's] vital component is the vibrato which causes a tone which is rigid and objective to tremble as if on its own; it ascribes to it subjective emotions without this being allowed to interrupt the fixedness of the basic sound-pattern, just as the syncopation is not allowed to interrupt the basic meter. (46)

He later suggests that the "jazz-sound itself [...] is determined by the possibility of letting the rigid vibrate, or more generally, by the opportunity to produce interferences between the rigid and the excessive" (46-47). For Adorno, the vibrato is a temporary fiction of subjective, individualized resistance against the confinements of a universalized modern existence, because it is always bound to the basic sound-pattern - or so the argument goes. His critique of syncopation is more elaborate. He argues that syncopation is a diversion from the capitalist mechanisms of the cultural industry, veiling the machinic, rigid, capitalist, military, fascist pre-dominance of the fundamental beat rather than subversively opposing it:

Syncopation is its rhythmic principle. It occurs in a variety of modifications, in addition to its elemental form (as the "cake walk," jazz's precursor, uses it), modifications which remain constantly permeated by this elemental form. The most commonly used modifications are the displacement of the basic rhythm through deletions (the Charleston) or slurring

28 He writes: "The wild antics of the first jazz bands from the South, New Orleans above all, and those from Chicago, have been toned down with the growth of commercialization and of the audience, and continued scholarly efforts to recover some of this original animation, whether called 'swing' or 'bebop,' inexorably succumb to commercial requirements and quickly lose their sting" ("Fashion" 119).

29 However, what appears a diffuse generalization is significantly valid in the sense that all US popular culture - even the notion of an American "popular" as such - can indeed be understood as Black, and Adorno's argument abjectively veers toward the specific Blackness of jazz. 
(Ragtime); ${ }^{30}$ "false" rhythm, more or less a treatment of common time as a result of three \& three \& two eight-notes, with the accent always on the first note of the group which stands out as a "false" beat (Scheintakt) from the principle rhythm; finally the "break," a cadence which is similar to an improvisation mostly at the end of the middle part two beats before the repetition of the principle part of the refrain. In all of these syncopations, which occasionally in virtuoso pieces yield an extraordinary complexity, the fundamental beat is rigorously maintained; it is marked over and over again by the bass drum. ("On Jazz" 45-46)

Because of these rhythmic and harmonic restrictions and the presumed fundamental acceptance of the symmetry ideal (metrical or harmonic), aesthetic innovation as much as subjective resistance is always already prefigured by an axiomatic definition of the expressible.

It follows for Adorno that true improvisation (axiomatically equated with innovation) is impossible in jazz, as it is pre-programmed and bound to patterns of modest range. In his view, the jazz musician is too restricted ever to transcend the "perennial sameness" of jazz, which does not allow for innovation but only exalts in "well-defined tricks, formulas and clichés" ("Fashion" 122). In "On Jazz" he writes: "Even the much-invoked improvisations, the 'hot' passages and breaks, are merely ornamental in their significance, and never part of the overall construction or determinant of the form" (53). Improvisations are always reducible to "the more or less feeble rehashing of basic formulas in which the schema shines through at every moment," which is apparently commonly understood because

any precocious American teenager knows that the routine today scarcely leaves any room for improvisation, and that what appears as spontaneity is in fact carefully planned out in advance with machinelike precision. But even where there is real improvisation, in oppositional groups which perhaps even today still indulge in such things out of sheer pleasure, the sole material remains popular songs. ("Fashion” 122)

30 This historical trajectory, whether culturally or musicologically valid, demonstrates that when talking jazz, Adorno talks Blackness - either by way of aesthetic trajectory or in the dismissal of US popular culture, that is, of white people imitating Black cultural practice. His aesthetic line of argument traces jazz back to previous Black popular cultural practices. Watkins writes: "By the 1910s, the cakewalk, "coon" songs, and ragtime music - all with inspiration or origin in black communities - had begun dominating America's popular entertainment." The influence was such that the "acceptance of the cakewalk by white Americans marked a major change in manners" and also "subsequent dance rages such as the Turkey Trot, Charleston, and Black Bottom (all with black origins) spurred the shift in white America's dance habits" (145). He further argued that "as whites increasingly copied black dance steps, black music with its emphasis on rhythm and syncopation also increased in popularity [...] making danceability the key to a song's potential." Watkin then provides much insight into the development of ragtime out of both "coon" and cakewalk songs (143-48). 
Okiji points out that the notion of individual resistance and individualism, as it refers to a bourgeois universalized self, says little about Black performance. She asserts that the

individual holds a problematic but central position in jazz narratives [...] Its use has assisted the desire to bring jazz closer to the model provided by Western European concert music and the singularity of the composer and her or his composition. It is an abstraction that leads to the fetishization of the solo as the essence of jazz work. (7)

Individualism in jazz discourse manifests the compositional paradigm in which an artist creates an artistic piece, a world, out of their individual potency. This potency is based on the impotence or the discursive incapacity to be a subject in the white modern matrical episteme for those racialized as Black. Whenever individualist compositionalism is the paradigm for analysis, the grammar of that analysis has no hold on the performance reality of Blackness on or off stage. Viewing jazz "through a lens that sees composition as the predominant site of artistry," idealizing autonomous and individualistic identities as (fictionally) manifest rationalized yet romanticized composition, and endowing them with the potential for political resistance, Adorno cannot but look down on what he interprets as "counterfeit identities" in jazz (Okiji 19). Okiji's analysis is central for understanding Adorno's argument through the lens of this project. Not only does Adorno activate the romantic idealism of high, bourgeois art (the Ancient stars, the Christian heavens, modern rational idealism) as opposed to the base, non-homogenous nadir of the earth and its popular cultural production. $^{31}$

Because of this active abjective ignorance, Adorno's modern bourgeois individualism and the compositional paradigm in which he formulates his critique both fall in line with Hitler Germany's propaganda. The first partial prohibition of jazz on German radio dates from 1933; the announcement by radio Berliner Funkstunde already invokes the idea of "degenerate art" and mobilizes hypersexualized negrophobia as well as the danceability of Black music as opposed to its aesthetics, which is linked to a vague notion of "German feeling":

The Berliner Funkstunde banishes all questionable dance music, described as [n-word] music by the healthy common sense of the people, in which a salacious rhythm prevails and the melody is raped. The Funkstunde will continue to cultivate modern dance

31 Interestingly, in his defense of "improvisation," white clarinetist Ted Gioia draws immediately from the matrical binary in naming his publication The Imperfect Art. 
music, as long as it is not inartistic in its musical elements or violates German sentiment. (qtd. in Fark 165, my translation) ${ }^{32}$

These ideas feature in Adorno's more elaborate jazz critique. His 1933 “Abschied vom Jazz" ("Farewell to Jazz") embraces the Nazi prohibition of jazz and an explicitly racial argument legitimized in the allegedly neutral terms of aesthetic quality judgment:

The regulation only confirmed by drastic verdict what has long since been decided on factual grounds: that jazz music itself has come to an end. Because no matter what you want to understand by white and [n-word] jazz, there is nothing to save here. Jazz has been hollowed out by its own stupidity. The regulation does not eliminate the musical influence of the [n-word] race on the northern one, and neither Cultural Bolshevism, but a piece of bad art. (qtd. in Fark 166, my translation) ${ }^{33}$

Adorno's logic actively partakes in Nazi cultural politics fueled by the notion of [n-word] jazz "raping melody," ultimately leading to its complete prohibition on the grounds that "[n-word] jazz" is corrosive and "destroys the foundation of our entire culture," as Fark quotes Reichssendeleiter Eugen Hadamowski (166).

On the grounds of both Hitler Germany's and the left-liberal anti-Black thought and affective structure, we can see how Adorno and the fascist propaganda machine have a common aim, a shared vector of self-making abjection. From a contemporary perspective, Adorno enters an uncanny alliance with fascist political action (resulting from propaganda about the racial sanitization of society that sought to eradicate the cultural influence of the "[n-word] race on the northern one"), veiling this abjectively powerful vector in an argument about aesthetic judgment. This constellation only appears more paradoxically absurd when Adorno uses jazz as a musical genre in which individual resistance is feigned to serve a fascist regime, based on what he reads as jazz's primary

32 "Die Berliner Funkstunde verbannt alle fragwürdige, vom gesunden Volksempfinden als '[nword]musik bezeichnete Tanzmusik, in der ein aufreizender Rhythmus vorherrscht und die Melodik vergewaltigt wird. Die Funkstunde wird aber auch weiterhin moderne Tanzmusik pflegen, soweit sie in ihren musikalischen Elementen nicht unkünstlerisch ist oder deutsches Empfinden verletzt."

33 "Die Verordnung [...] hat [...] nur durchs drastische Verdikt bestätigt, was sachlich längst entschieden ist: das Ende der Jazzmusik selber. Denn gleichgültig, was man unter weißen und unter [n-word]jazz verstehen will, hier gibt es nichts zu retten [...] Was [...] den Jazz aushöhlte, ist eine eigene Stupidität. Mit ihm wird nicht der musikalische Einfluss der [N-wort]rasse auf die nördliche ausgemerzt; auch kein Kulturbolschewismus, sondern ein Stück schlechtes Kunstgewerbe." 
rhythmic structure and instrumentation and making this tendency toward abstract fascism his central culturo-musicological criticism:

The effectiveness of the principle of march music in jazz is evident. The basic rhythm of the continuo and the bass drum is completely in sync with march rhythm, and, since the introduction of six-eight time, jazz could be transformed effortlessly into a march. The connection here is historically grounded; one of the horns used in jazz is called the Sousaphone, after the march composer. Not only the saxophone has been borrowed from the military orchestra; the entire arrangement of the jazz orchestra, in terms of the melodic, bass, "obligatory," and mere filler instruments, is identical to that of a military band. Thus jazz can be easily adapted for use by fascism. ("On Jazz" 61)

Adorno's argument aligns with historical fascism in an anti-Black affective thrust in 1933, using the same abjective procedure to generate a metaphor of jazz as a model for the workings of fascism after World War II. Unsurprisingly, comparable querfront alignments occur in contemporary debates on the artistic value and moral judgment of hip-hop culture, especially gangsta rap. Here too left-liberal criticism (journalistic or academic) and racist common sense abject Black cultural production, reinforcing each other on common ground. However, rather than falling for the moral argument, I engage with Adorno's elaborations on their own turf. Given Germany's history, Adorno set out to devise a theory of resistance after Auschwitz, seeking to generate an aesthetic position from which actual resistance would be possible, where political action and negotiability as such were thinkable. Even though he might not have used terms like "betterment," "progress," or "improvement," his argument is necessarily positioned on the plane of political negotiation and linear development. He therefore partakes in what Warren would call a politics of hope within the sphere of governmentality, again facilitated by anti-Blackness.

\section{"Feigned subjectivity"}

For Adorno, jazz symbolizes the relationship between economy and culture. The industry of commodification knows art or artistic expression only as amusement, and the capitalist system generates dynamics that commodify resistance. These aesthetic arguments cannot be distinguished from his political project of restoring the modern subject after the atrocities it caused in World War II. For Adorno, such moral reassurance is possible via art as resistance. Unlike whatever happens in the lofty realms of high art, he argues, commodified cultural expression like jazz can never self-empower the subject. Political opposition can never be achieved because, structurally, it does not come from a place that offers the capacity for such actual opposition. On this larger scale, Adorno suggests that jazz 
performs "a subjectivity which revolts against a collective power which it itself is; for this reason, its revolt seems ridiculous and is beaten down by the drum just as syncopation is by the beat" (“On Jazz" 68). The brief English-language summary at the end of the original publication of "Über Jazz," under the pseudonym Hektor Rottweiler, is succinct: "The antagonistic character of jazz is expressed by the formula that the 'subject of jazz' permits itself to be annihilated by society in order to feel itself endorsed and vindicated by society" (258). In the “Oxforder Nachträge," an addendum to "Über Jazz" published in Gesammelte Werke, Adorno writes: "What is crucial about the jazz-subject is, that despite its individual character, it does not own itself at all” ("Über Jazz” 258, emphasis mine).

Those who have engaged with the legacies of slavery cannot but hear the anti-Blackness of such a formulation. But we may also ask: exactly who is meant by the “jazz-subject?" In a footnote, Okiji addresses this “real confusion about what subject is being referred to at various points in 'Über Jazz,", which leads some to think that the subject in question is the bourgeois consumer of jazz, and others to think of the (Black) musician as that subject. Okiji interprets this as both a theoretical and rhetorical device, pointing to the "implications when Adorno talks of castration, clowns, and slaves, especially when we're told of 'oppressed people' being particularly well-adapted for jazz and life und monopolized capitalism" (101). Even though Adorno regularly makes the point that jazz does not represent some sort of originary Blackness, it would be a compulsively contrived position to delink Blackness from the argument, especially in his assumption of jazz's natural servility, as formulated for example in "On Jazz":

Psychologically, the primal structure of jazz (Ur-Jazz) may most closely suggest the spontaneous singing of servant girls. Society has drawn its vital music - provided that it has not been made to order from the very beginning - not from the wild, but from the domesticated body in bondage. The sadomasochistic elements in jazz could be clearly connected to this. (“On Jazz” 53)

Moreover, Adorno emphasizes that it is not external market forces or sociopolitical structures but jazz and its practitioners themselves that are to be blamed; their submission is part of their being-in-the-world. Jazz is by its aesthetic modality authority-bound, in the oedipal Freudian sense:

However little doubt there can be regarding the African elements in jazz, it is no less certain that everything unruly in it was from the very beginning integrated into a strict scheme, that its rebellious gestures are accompanied by the tendency to blind obeisance, much like the sadomasochistic type described by analytic psychology, the person who chafes 
against the father-figure while secretly admiring him, who seeks to emulate him and in turn derives enjoyment from the subordination he overtly detests [...] It is not as though scurrilous businessmen have corrupted the voice of nature by attacking it from without; jazz takes care of this all by itself. ("Fashion" 121)

In view of jazz's Blackness, Adorno moves to a tendentious, bawdry castration of Blackness to showcase his own enlightened, high art, European potency:

The syncopation [in jazz] is not, like its counter-part, that of Beethoven, the expression of an accumulated subjective force which directed itself against authority until it had produced a new law out of itself. It is purposeless; it leads nowhere and is arbitrarily withdrawn by an undialectical, mathematical incorporation into the beat. It is plainly a "coming-too- early," just as anxiety leads to premature orgasm, just as impotence expresses itself through premature and incomplete orgasm. ("On Jazz" 66)

In "Perennial Fashion" he goes even further:

The aim of jazz is the mechanical reproduction of a regressive moment, a castration symbolism. "Give up your masculinity, let yourself be castrated," the eunuch-like sound of the jazz band both mocks and proclaims, "and you will be rewarded, accepted into a fraternity which shares the mystery of impotence with you, a mystery revealed at the moment of the initiation rite." (128-29)

In this line of thought, it follows that the jazz subject exists only as "the amalgam of a destroyed subjectivity and of the social power which produces it, eliminates it, and objectifies it through this elimination" ("On Jazz" 67). When it does express itself, it says "I am nothing, I am filth, no matter what they do to me, it serves me right” ("Fashion” 131).

But who ever said that one could derive the psychological pathology of a subject from a rhythmic structure? And why blow that fantasy up and map it metonymically onto collective cultural spaces, abjected or not? Most of Adorno's interpreters, apologists and critics alike, seem to adopt this far-fetched and highly consequential assumption, which has some grotesque excrescences. For example, Adorno states that "[j]azz and pogrom belong together" implying that the jazz-subject is either naturally fit for being pogromed or a stupid enough exception that consciously and voluntarily engages in jazz one way or another ("Über Jazz," Gesammelte Werke 101, my translation). Some lines of logic become almost facetious, as when Adorno treats his conceptual analogy as causality in the following lofty statements:

I clearly remember how shocked I was when I first read the word "jazz." It would be plausible that it comes from the German word "Hatz," sketching the pursuit of a slow dog by bloodhounds. The typeface appears to contain the same castration threat as that of the 
jazz orchestra with the grand piano's open lid [...] The name of jazz's final predecessor also belongs in the same context: ragtime [...] The "ragging of time" by the syncope is ambivalent. It is an expression of an oppositional feigned subjectivity revolting against the measure of time, and simultaneously that of a regression mapped out by the objective instance. (“Über Jazz," Gesammelte Werke 102, my translation) ${ }^{34}$

Many elements of this line of argument are worth pointing out: the repetition of an alleged castration threat that speaks to culture and society through a musicological argument; the assumptive positing of an aesthetic trajectory in which the predecessor, like jazz, is presented as regressive; the etymological coercion and grotesque (non!-)causality that Adorno performs to satisfy the logic of the argument. The last point crystallizes the argumentational performance of his jazz critique writ large. Even though etymological arguments of this kind always need to be considered with extreme caution, by relating the German "Hatz" and the English "jazz," Adorno's argument becomes idiosyncratic rather than providing the structural analysis he seeks. The logic (metaphor, simile, analogy, causality?) only operates at all when "jazz" is pronounced with a particularly strong German accent. It is safe to say that strong German accents have no causal bearings on the history of jazz, its aesthetics, social formations, actual performances, or anything else related to it. Yet within his argument, it simply fits: Adorno takes an English language term and articulates it in his own language to make it fit his own theorization and the axiomatic, a priori ground specific to it, actively ignoring what would be potential ("plausible") limitations - also specific to it. What appears to be a grotesque distortion of the facts and a violent coercion of reality turns out to be a succinct example of the solipsism of modern white critical thought. Regardless of one's position on popular culture and the Blackness by which it exists, it cannot be talked about without overt or covert, conscious or unconscious reference to this very Blackness. The racial absurdities and violent de-humanizations (un-subjectivations, de-masculations) that constitute Adorno's logic right up to the preposterous Hatz-jazz-etymology are not wounds or mishaps in the larger argument. They cannot (and do not need to be) excused on the grounds that Adorno had no real (or not much) knowledge about jazz,

34 "Ich erinnere mich deutlich, daß ich erschrak, als ich das Wort Jazz zum ersten Male las. Plausibel wäre, daß es vom deutschen Wort Hatz kommt und die Verfolgung eines Langsameren durch Bluthunde entwirft. Jedenfalls scheint das Schriftbild die gleiche Kastrationsbedrohung $\mathrm{zu}$ enthalten, die das des Jazzorchesters mit dem aufgesperrten Flügeldeckel darstellt [...] In den gleichen Zusammenhang fällt gehört der Name für die letzte Vorform des Jazz: Ragtime [...] Das "Zerfetzen der Zeit” durch die Synkope ist ambivalent. Es ist zugleich Ausdruck der opponierenden Scheinsubjektivität, die gegen das Maß der Zeit aufbegehrt, und der von der objektiven Instanz vorgezeichneten Regression.” 
or whatever other reasons have been marshalled in his defense. Rather, we need to recognize that they make complete sense within Adorno's logic - and in the logic of those who draw from it, defend it, and apply it. Whoever wishes to understand Adorno's cultural critique may easily turn to jazz as his concrete model.

Unlike contemporary exegetes, who usually do not know how to deal with Adorno's analysis of jazz, his own contemporaries were less tentative. In a letter to Adorno, Max Horkheimer expresses favor for his first essay on jazz, which he thinks a "particularly excellent study" of an "apparently insignificant phenomenon." Horkheimer states that the essay was well-received within the Frankfurt School circle for its "formulations of extraordinary precision and brilliance" (qtd. in Paetzold 79, my translation). In his extensive defense of Adorno's writings on jazz, Paetzold writes: “Adorno's analysis of jazz [...] serves as a model for all criticism of the cultural industry, some of which was only carried out later" (77, my translation). ${ }^{35}$ We must take Adorno's racial arguments seriously because both superficially and deep-down they make so much sense - Adorno's readership, being active sense-makers, consciously or subconsciously abject Blackness along with him. The affective shortcut of anti-Black abjection makes it work. Subconsciously, he can map his argument on Blackness, where the white subject always finds discursive "servility," on commodified Black bodies consequently bearing feigned subjectivities at best. The metaphor works because Adorno has Blackness labor for it. In this way, we must recognize that, even if it looks like a simplification, the notion of natural Black servility is the affectively axiomatic fixed point of reference from which his argument draws its coherence. His continual reference to jazz as "[n-word] music" or "[n-word] jazz" is often explained or even excused by white scholars as the "language of his time." Such contentions, however, miss the functional role of such vocabulary in the affective dimension of the larger argument. The n-word has been translated into English as "Negro" and later as "black," neither of which sets free the full abjective force Adorno generates by his repeated use of the n-word. However, his lexicality undermines the assumed intellectualist purity of what has been argued to be an aesthetic, musicological argument.

Adorno's jazz critique is white academic abjectorship par excellence because his fascination with Black cultural production is out in the open, revealing the libidinal energy shaped as the desire to deal repeatedly with jazz as well as the symbolic castration of Blackness in order to reassert oneself. Such sexualized language in scholarly prose speaks to the libidinal project of anti-Black abjec-

35 “Adorno’s Analyse des Jazz [...] dient als Modell für alle, teilweise erst später ausgeführte Kritik der Kulturindustrie." 
tion, in which Adorno participates by way of dehumanization and demasculation. His sexualized language is not accidental but functions as a deep-set, libidinal, abjective defense mechanism in view of hypersexualized, phobic Blackness. Adorno was in dire need of a subject-aeffect, which he (presumably) achieved by anti-Black abjection. Ultimately, his defense of a resistant, autonomous subject expressed through art is an ontological dead end. Everything he states about popular culture rings "true-for" white mass entertainment today. There is as little doubt about the marketability of popular culture as commodity as there is a belief in the possibility or relevance of actual resistance. There is a lot of feigned autonomy and pretend individuality in current popular cultural production, regardless of how it is morally judged. This is significant when we look at the Blackness of all popular culture because it appears to imply that Adorno was right in his analysis of jazz in the sense that what he sees in jazz from a white position is what any other white mind can see - including those who imitate, capitalize upon, and consume popular culture's Blackness, even though it may not be acknowledged as such. If all popular art derives from a dehumanizing misinterpretation of Black forms, perhaps grounded in the compositional register of high, white art, then an equally dehumanizing critique of these forms would be correct in its attack on a generalized popular culture. However, Adorno's critique, even if validated this way, is inconsequential and has lost its grasp on contemporary life. This may sound provocative to those who despise contemporary popular mass culture, who claim that Adorno is more relevant now than ever. I suggest that we must recognize popular culture as a fact, and as a Black one at that. This fact is central to the system of abjectorship by which white subjects desire and live.

The concession of popular culture as a fact (rather than something adversarial to overcome or negotiate with) is the only way we can make this debate at all productive again, which takes us back to the non-relationship between Blackness and Humanity. The anti-Black system of the modern West allows Black people to access the world only as ownable, tradeable commodities. In his argument, Adorno criticizes the commodity for being a commodity so as not to turn into a commodity himself. He can only do so by vibrant anti-Black abjection, by ensuring that the commodity and commodification are elsewhere, namely in Blackness: "With jazz, a disenfranchised subjectivity plunges from the commodity world into the commodity world; the system does not allow for a way out" ("On Jazz" 54). Ultimately, Adorno believes he can save the bourgeois subject by revamping the logic that brought it about in the first place, positing a fundamental, categorical difference and racial hierarchy between autonomous subjects and those who willfully and naturally let themselves be ruled, between 12tone music and jazz, between Humans and property, whites and Blacks. By en- 
gaging in the register of governmentality (including resistance against it), Adorno stays within the logic of anti-Black abjection as he denounces popular culture for its Blackness. I suggest that we white scholars should not dabble in analyses of jazz as Adorno does, but consider what the fact of (Black) popular culture says about how we are currently being human. Speaking from the position of white subjectivity, however, Adorno's recognition of the ways in which Blackness is mobilized to cause affect in the popular is spot on. One of the quotations from his jazz critique that tends to meet with a lot of criticism is his statement that "the skin of the black man functions as much as a coloristic effect as does the silver of the saxophone" ("On Jazz" 53). While the condemnation of this sentence is understandable, its racial calling out is significant, and provides part of an answer to Kennel Jackson's question in Black Cultural Traffic: "What [...] is it about black cultural material, performances, and representations that puts them in such demand" $(19-20) ?^{36}$

\section{The currency of commodified affect}

In "The Question of [ $\left.\mathrm{N}^{\star \star \star} \mathrm{a}\right]$ Authenticity," Ronald Judy considers the mainstream critique of rap, and by extension hip-hop, as a social malaise that revolves around notions of misogyny, obscenity, violence, and bling bling culture. He dismisses the moral grounds of this criticism by asserting that it assumes Blackness to be a sphere of subjective (and subsequently moral) capacity in the first place. Because this is not the case, moral law does not provide an applicable register for the judgment of Black cultural production, and there is no foundation for demanding a "morally legitimate form of rap" (216). Judy suggests doing away with the superficial "question of [rap's] historical and ideological significance for African American society" on the grounds that this question implicitly seeks to insert a cultural core into the sphere of Blackness, allowing for an optimistic telos such as "the liberation of humans as subjects of knowledge from the subject of experience, from the commodified [n-word] of slavery" (217). Instead, Judy proposes that we recognize the impossibility of a "Black subject" and think of hard-

36 For Jackson, the notion of Black cultural traffic, though it has many forms, "always presupposes movement of cultural matter [and] involves some system of commerce or exchange." He makes sure it is understood that "when we speak of Black cultural traffic, we are always implying the traveling not of whole cultures but elements - even microelements" (8). Thinking about elements - be they microelements, artefactual, or ephemeral - we get closer to the idea of popular culture, in its historical legacy and libidinal structure, as the very Blackness that provides white subjectivity with reinvigorating force and subject-effects of all intensities qua anti-Black abjection. 
core rap "with the commodified [ $\left.n^{\star \star \star} a\right]$," which is a threat "in exhibiting the groundlessness of the sovereign individual” (225). The presence of the hardcore rapper who traffics in the affect they trigger "indicates the identification of human with thing, that the human can only be among things, cannot be beyond or abstracted from things."

In Judy's argument, the [ $n^{\star \star \star} a$ ] is a transumption of the "bad [n-word]" not because it signifies criminality (a line of thought Judy describes as "regressive"), but because it opens the possibility of investigating authenticity as such. The "regressive thought" of modern subjectification and governmentality, of political and moral subjectivity, of experience as the ground of Humanity, "cannot comprehend the hard-core [ $\left.n^{\star \star \star} \mathrm{a}\right]$ " because experience as such is "inevitabl[y] los[t] to commodified affect" (227). Whether popular culture is good or bad is irrelevant. These categories belong to the regressive register of white, modern political morality:

This is the age of hypercommodification, in which experience has not become commodified, it is commodification, and [ $\left.\mathrm{N}^{\star \star \star} \mathrm{a}\right]$ designates the scene, par excellence, of commodification, where one is among commodities. $\left[\mathrm{N}^{\star \star \star} \mathrm{a}\right]$ is a commodity affect. [...] A [ $\left.\mathrm{n}^{\star \star \star} \mathrm{a}\right]$ forgets feelings, recognizing, instead, that affects are communicable, particularly hard-core ones of anger, rage, intense pleasure. [T]he hard-core rapper traffics in affect not values. $(227-28)$

This argument would be hard to swallow for Adorno, especially because much of it would, in fact, be intelligible to him. Neither Adorno nor Judy believes (or is interested) in an expressive cultural core, a reducible meaning of Blackness. Both recognize the commodification involved in popular culture as a commodification of psychological and biochemical sensations. Yet speaking at a time when popular culture's hypercommodification is no longer a threat but a fact, Judy's position exposes as regressive Adorno's defense of the bourgeois subject, of political hope (to use Warren's term), of governmentality and resistant opposition, his belief in the possibility of real authenticity, of possibility itself. Unlike Adorno, though, Judy is disinvested in white subjectivity. He has nothing to gain from the idea of autonomous or authentic art, from the notion of Human resistance on political and moral grounds, and so he can theorize popular culture with less emotional judgment. Judy's hardcore rapper, located in the discursive sphere of Blackness, provides a more substantial and workable concept of authenticity as a tradeable affect, which ultimately provides the galvanizing ground for popular cultural production, activity, and trade:

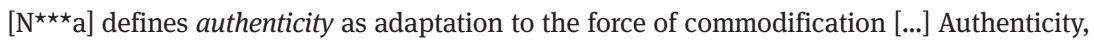
then, is produced as the value that everybody wants precisely because of the displacement 
of political economy with economy [...] Authenticity is a hype, a hypercommodified affect [...] [ $\left.\mathrm{N}^{\star \star \star} \mathrm{a}\right]$ is not an essential identity, strategic or otherwise, but rather indicates the historicity of indeterminate identity. (229)

Judy's concept "poses an existential problem that concerns what it means (or how it is possible) to be human" because it rejects modern subjectivity as we know it $(229-30)$. 